\title{
ANÁLISIS DEL PAISAJE FÍSICO Y HUMANO DE LA PROVINCIA \\ DE ALICANTE: GOOGLE EARTH COMO HERRAMIENTA DOCENTE EN LAS CLASES DE GEOGRAFÍA
}

\author{
Isabel $\mathrm{M}^{\mathrm{a}}$ Gómez Trigueros. Estudiante de Doctorado del Departamento de Geografía \\ Humana. Universidad de Alicante. (España) y profesora de enseñanza secundaria en \\ I.E.S. de Agost (Alicante, España) \\ Correo electrónico: isagomtri@hotmail.com
}

Recibido: 18 de noviembre de 2010. Aceptado: 28 de noviembre de 2010.

\begin{abstract}
RESUMEN
Las Nuevas Tecnologías de la Información y la Comunicación (TIC's) lo impregnan todo, incluida la enseñanza. La incorporación de Google Earth como herramienta para las clases de Ciencias Sociales, concretamente de Geografía, supone una nueva manera de aprender y de trabajar con el alumnado. Para el profesorado supone una nueva forma de enseñar el medio físico y humano a los estudiantes, observando el espacio más cercano, vivido y sirviéndole de base en sus explicaciones teóricas. Es, pues, un modo nuevo de enseñar que combina la teoría y la praxis, logrando que el alumnado cambie su idea tradicional respecto de la Geografía viéndola ahora como una disciplina global, no sesgada, indivisible, cercana y útil.

Palabras clave: Google Earth, TIC's, Geografía, herramienta, Enseñanza Secundaria Obligatoria.
\end{abstract}

\begin{abstract}
The New Technologies of the Information and Communication (ICT's) permeate every aspect, including teaching. The incorporation of Google Earth as a tool for the classes of Social Sciences, particularly of Geography, is a new way to learn and work with students. For teachers is a new way of teaching to students the physical and human environment, noting the closest space, and serving as base in their theoretical explanations. It is therefore a new way of teaching that combines theory and practice, making the students change the traditional idea about Geography, seeing it now as a global discipline, unbiased, indivisible, close and helpful.
\end{abstract}

Key words: Google Earth, ICT's, Geography, tool, secondary education mandatory.

\section{INTRODUCCIÓN}

En el momento actual en el que vivimos resulta imprescindible contar con la informática y, dentro de ella, con Internet, para poder conocer y aprender qué sucede en nuestro entorno físico y humano. El uso de Internet para el conocimiento de todo lo que nos rodea, aquello que sucede, lo que aparece nuevo y también se destruye, etc. también se hace patente para poder enseñar Geografía e Historia al alumnado en general y, al de enseñanzas medias, muy en particular. El empleo de estas nuevas tecnologías como Internet para el aula o, lo que es lo mismo, la informatización de la educación secundaria obligatoria, supone, desde nuestro punto de vista, un empuje a las grandes posibilidades del ser humano y de su capacidad para aprender.

La enseñanza actual se ha modificado. El profesorado ha dejado de ser un transmisor sin más de conocimientos. Hemos dejado atrás una enseñanza mecánica basada en la repetición. Ahora, la enseñanza es un aprendizaje activo, reflexivo y crítico. Toda vez 
que la educación actual es un enlace directo a la vida y al trabajo es pues necesario que los profesores utilicen y motiven al alumnado en el uso y manejo de aquellas herramientas que le ayuden a ser personas emprendedoras y con un desarrollo de su potencial intelectual. Esta sería pues la función de las TIC's, formar de manera integral no sólo con conocimientos teóricos sacados de manuales sino también con el trabajo de campo directo a través de la información que puede aportar Internet. La introducción de las TIC en el mundo educativo y el "nuevo modelo" de enseñanza-aprendizaje, que hace hincapié en tres pilares: 1) El alumnado debe descubrir la información de manera que sea él quien conduce su propia aprendizaje; 2) Emplea, como medio de expresión de sus ideas (y aprendizajes) las nuevas tecnologías; 3) Interactuar con "otros" transmitiendo, compartiendo, formulando e intercambiando ideas y conocimientos, obliga a los profesores-educadores-formadores a adaptarse a estos cambios tecnológicos y vitales de la sociedad de la información.

Y es que la manera de dar clase haya cambiado sustancialmente. La labor didáctica partiría pues más del profesorado y del alumnado que de otros elementos externos como el libro de texto o las páginas Web tradicionales y unidireccionales. La "nueva escuela" utiliza, por ejemplo, herramientas de apoyo para la comunicación (foros, proyectos telemáticos, comunidades virtuales) y herramientas para la elaboración de trabajos propios o colaborativos (creación de presentaciones, blogs, uso de programas libres para elaborar actividades propias, trabajos a partir de Webquests, introducción en redes colaborativas, participación en Wikis, etc.). Es en este segundo apartado donde tiene cabida el uso del Google Earth como herramienta imprescindible ya, en las clases de ciencias sociales.

Ante esta nueva situación se planteó poner en marcha un proyecto que, a partir de la herramienta Google Earth, permitiera desarrollar el currículo de Geografía e Historia, de secundaria en la Comunidad Valenciana. Dicho proyecto se diseñó para un curso escolar (nueve meses). Los grupos con los que se ha trabajado han sido de primer y segundo ciclo de ESO (dos grupos de $1^{\circ}$ y $2^{\circ}$ de ESO y dos grupos de $3^{\circ}$ de ESO) y de $2^{\circ}$ de Bachillerato, dentro del área de Geografía. Estos grupos estaban compuestos por veinte o veinticinco alumnos. La manera de desarrollar dicho proyecto ha sido a través de mini proyectos compaginando las sesiones teóricas en el aula de Ciencias Sociales (dos sesiones semanales) y las prácticas (una sesión semanal) en el aula de Informática y a través de la herramienta Google Earth. Se ha logrado así unir teoría y práctica y algo muy importante, conseguir una visión global de la Geografía, estudiando de manera unísona la parte física y humana de esta ciencia en lugar del modelo sesgado de los libros de texto y planes de estudio.

\section{¿QUÉ ES GOOGLE EARTH?}

Dentro del ámbito de las Ciencias Sociales se cuenta con una nueva tecnología de Internet que permite observar, comparar, analizar, diferenciar, elaborar y alcanzar los conocimientos del área de la Geografía (y también de la Historia). Esta nueva herramienta es Google Earth y proporciona la posibilidad de acceder al aspecto físico externo de la Tierra y, a partir de él, organizar conocimientos que sin una observación directa del fenómeno quedarían vacíos de sentido y poco útiles para el alumnado. Se trata de un programa ciertamente innovador que puede permitir a los alumnos de secundaria optimizar los procesos de aprendizaje de la Geografía (y también de la Historia). 
Según la definición oficial ${ }^{1}$ Google Earth es: un programa informático similar a un Sistema de Información Geográfica (SIG), creado por la empresa Keyhole Inc., que permite visualizar imágenes en 3D del planeta, combinando imágenes de satélite, mapas y el motor de búsqueda de Google que permite ver imágenes a escala de un lugar específico del planeta. Apareció con este nombre en mayo de 2005, cuenta con diferentes versiones y ha ido cambiando, a través de su estructura de Web 2.0, gracias a la participación de los usuarios. Podemos incluir versión de pago y gratuita, con diferentes prestaciones según se trate de una u otra.

Siguiendo con los análisis pedagógicos, se considera que la aplicación de la Informática en las Ciencias Sociales puede llegar a desarrollar programas educativos que permitan un buen desarrollo integral del alumnado ya que, según apuntó Piaget sobre la madurez intelectual, la única manera de iniciarse en el conocimiento epistemológico es a través de la metodología experimental, esto es, que el alumno tenga contacto directo con aquello que estudia. Google Earth no permite al alumnado "tocar directamente" un suelo cárstico o un trazado medieval de una ciudad pero sí le proporciona la observación directa del fenómeno en tiempo casi real y con imágenes cercanas a él (conocimiento constructivista sobre aquello que el alumno conoce o percibe como próximo).

\section{OBJETIVOS PLANTEADOS EN EL PROYECTO}

Se deben diferenciar dos bloques de objetivos planteados en este proyecto de investigación. Los primeros serían los objetivos generales (la introducción de una nueva herramienta, Google Earth, para enseñar Ciencias Sociales) y los segundos los específicos, más concretos pero igualmente evaluables (la consecución, a través de clases prácticas y teóricas, de los contenidos marcados en el currículo para secundaria obligatoria, en la Comunidad Valenciana). Estos últimos son, en resumen los siguientes:

a) Conocer el aspecto actual que presenta el paisaje de la Comunidad Valenciana y, concretamente de la provincia de Alicante, desde el punto de vista de la Geografía Física (formaciones del relieve, estructuras geológicas, redes hidrográficas, poblamientos vegetales, etc.) y de la Geografía Humana (espacios actuales en cultivo, tipos de cultivos, aspecto que presentan, estructuras y formas de organizar el espacio rural, estructura urbana, vías de comunicación, distribución industrial, infraestructuras de transporte, espacios turísticos, etc.).

b) Diferenciar usos del suelo a lo largo del tiempo en la provincia de Alicante, comparando el aspecto y usos actuales con usos anteriores a través de la cartografía existente y Google Earth.

c) Analizar los diferentes paisajes geográficos de la provincia de Alicante, tanto desde la óptica del espacio físico como desde la perspectiva urbana y agrorrural.

d) Observar e interactuar con la Tierra y, en concreto con la provincia de Alicante, tanto desde una perspectiva espacial (Google Earth ofrece la posibilidad de "sobrevolar" el mundo) como tridimensional, es decir, trabajar directamente con volúmenes y relieves reales.

e) Realizar mediciones y utilizar las coordenadas geográficas para trabajar y estudiar el clima de la provincia de Alicante y compararlo con el del resto de la Comunidad Valenciana, España y el mundo. 
Respecto de los primeros, se consideró que la manera de introducir el tema de Google Earth como una herramienta más para las clases de Ciencias Sociales fuera la instalación del programa en los ordenadores del aula de Informática por parte de los propios alumnos. El resto del trabajo que llevaron a cabo con dicho herramienta (Google Earth) se encontraba en un CD donde el alumnado iba guardando y recuperando, según fuera necesario, las diferentes tareas.

En cuanto a los segundos, los objetivos específicos han estado totalmente vinculados a la enseñanza-aprendizaje del currículo. En el Cuadro 1 un ejemplo de los bloques de trabajo para $1^{\circ}$ de ESO en forma de tabla. Esta tabla consta de tres pilares en torno a los que se ha desarrollado este proyecto y que están en total consonancia con el currículo de cada nivel. Así, en al primera columna aparece el bloque temático desarrollado, dentro del currículo del nivel concreto de enseñanza secundaria obligatoria. La segunda columna señala, dentro de dicho currículo, qué objetivos se marcan por ley y que criterios de evaluación (o calificación) se deben tener en cuenta (y de hecho se han tenido en cuenta en este proyecto). En la tercera columna aparecen los objetivos que se marcaron dentro del proyecto y que se han desarrollado con cada una de las actividades creadas con Google Earth.

Como se puede apreciar, los objetivos que se marcaron con este proyecto son mucho más amplios y abarcan más de un bloque temático. Se insiste en que este trabajo de investigación, ha combinado y relacionado aspectos que tradicionalmente se han trabajado de forma aislada y que no han permitido al alumnado hacerse con una visión general de lo aprendido. Además, esta manera de enfocar el currículo y los objetivos, ha permitido, como se puede ver en la evaluación realizada, considerar a la Geografía como un área útil y práctica para la vida diaria. Si bien cabe destacar que los resultados han sido positivos o muy positivos según se hable de bachillerato o de secundaria obligatoria. 


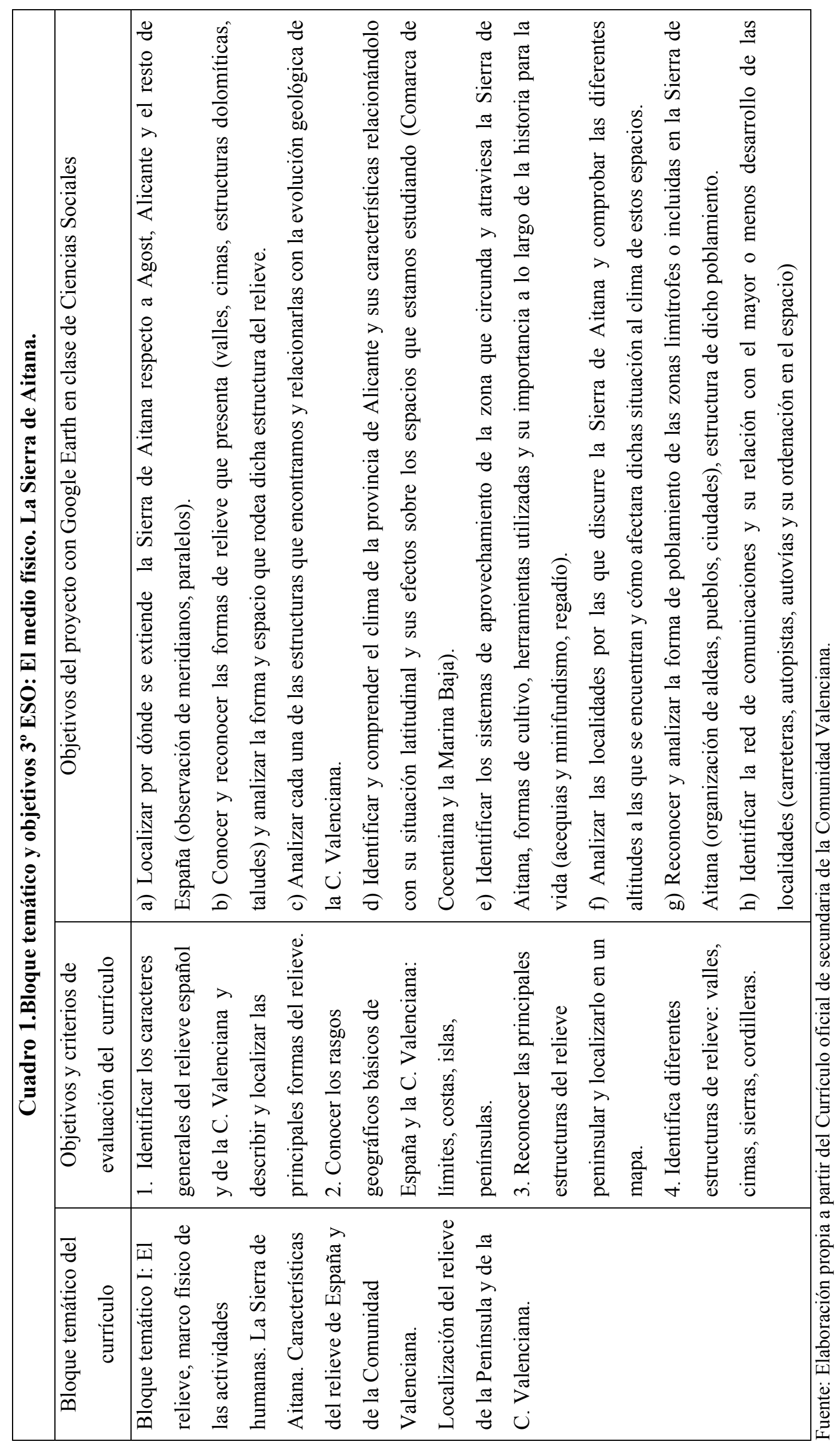




\section{METODOLOGÍA DEL PROYECTO DE TRABAJO}

El proceso de investigación ha seguido así los siguientes pasos en cuanto a fuentes y recursos utilizados en dicho proyecto: De un lado, trabajo de campo basado en la búsqueda de información en fuentes catastrales y cartográficas (Instituto Cartográfico Valenciano, el Instituto Geográfico Nacional, el Ministerio de Medio Ambiente y Medio Rural y Marino, la Dirección General de Catastro dependiente del Ministerio de Hacienda, el Instituto Cartográfico de Cataluña) con la intención de obtener información de este tipo sobre la provincia de Alicante. De otro lado, la búsqueda de información referente a usos y nuevas aplicaciones de las TIC's, y más concretamente del Google Earth para la enseñanza de las Ciencias Sociales.

Como hemos señalado antes, el marco de desarrollo de este proyecto ha sido un centro de secundaria, de la provincia de Alicante. El proyecto de trabajo ha incluido dos grupos de $1^{\circ}, 2^{\circ}$ y $3^{\circ}$ de ESO y un grupo de $2^{\circ}$ de Bachillerato del área de Geografía. La forma de organizar el trabajo se ha ajustado totalmente al currículo de secundaria para cada uno de los niveles. La duración marcada ha sido la de un curso escolar completo, nueve meses, comenzando en septiembre y terminando en junio. Para la organización del proyecto y el espacio (aulas) se tuvo en cuenta el número de horas de cada uno de los grupos, el número de alumnado por grupo y la disponibilidad del aula de Informática. Cada grupo oscilaba entre veinte y veinticinco alumnos, de características diferentes. En cada uno de estos grupos se imparten tres horas semanales de Geografía e Historia respectivamente a excepción de $2^{\circ}$ de Bachillerato que es de cuatro. Por ello, se diseñó este proyecto de trabajo con la impartición de dos horas teóricas en el aula de referencia de cada grupo y una hora semanal en el aula de Informática.

Se debe reseñar que, para $2^{\circ}$ de Bachillerato, se ha dedicado sólo una sesión semanal de manera discrecional, a completar y ampliar conocimientos con Google Earth. La razón es que estos alumnos tienen como objetivo final los exámenes de la PAU y se hacia complicado dedicar una sesión semanal, durante todo el curso, por la necesidad de tiempo para alcanzar la plena consecución del currículo de Geografía de Bachillerato. De ahí que se haya trabajado dos sesiones al mes con Google Earth en lugar de cuatro como ha ocurrido con el resto de grupos de ESO.

Este plan ha constado de una parte teórica y otra práctica. Lo interesante de la puesta en marcha de este proyecto de trabajo con el alumnado, ha sido la interrelación de ambas partes, teoría y praxis, de manera que una sin la otra no tienen sentido. Así, mientras en la clase de Geografía se analizaban, conceptos puramente teóricos, en el aula de Informática (donde tenemos instalado el programa Google Earth) se ponían en práctica la observación, análisis, descripción, interrelación, etc. de todos esos conceptos y su plasmación real sobre la superficie de la Tierra y, en concreto, en la provincia de Alicante, donde pusimos en marcha este proyecto. De esta manera se trabajaban, durante dos sesiones, los contenidos conceptuales y de procedimiento y, durante la sesión que se imparte en el aula de informática con Google Earth se profundizaba tanto en los conceptos como en los procedimientos ya previamente aprendidos.

Al tratarse de grupos heterogéneos, el trabajo podía variar dependiendo del seguimiento que cada uno de ellos llevara a cabo a lo largo del proceso de aprendizaje y trabajo con Google Earth. Por ello se diseñó un cuadernillo de trabajo para todo el alumnado con que trabajamos acompañado de un CD regrabable donde aparecían: 
- Los bloques temáticos que se iban a desarrollar con su secuenciación (según su inserción en el currículo de Ciencias Sociales de secundaria).

- Un pequeño manual sobre el uso de Google Earth.

- Actividades o "proyectos de trabajo".

En estos CD regrabables cada alumno iría guardando todas las actividades realizadas en las clases prácticas de Google Earth, donde se dejaba constancia de la fecha y hora en la que se realizaban. De esta manera cada alumno podía retomar las actividades donde las había dejado en sesiones anteriores.

Los contenidos teórico-prácticos marcados en el currículo ${ }^{2}$ de la enseñanza secundaria del área de Ciencias Sociales son, grosso modo, los siguientes:

- $\quad 1^{\circ}$ de ESO: aspectos de Geografía Física del mundo, España y la Comunidad Valenciana y de Historia (hasta las invasiones bárbaras de la Península Ibérica).

- $\quad 2^{\circ}$ de ESO: aspecto de Historia (Antigua y Medieval) del mundo, España y la Comunidad Valenciana.

- $\quad 3^{\circ}$ de ESO: aspectos de Geografía Física y Geografía Humana del mundo, Europa, España y la Comunidad Valenciana.

- $2^{0}$ de Bachillerato, área de Geografía: aspectos de Geografía Física y Geografía Humana de España (y la Comunidad Valenciana).

El modo de trabajar con Google Earth ha sido mediante pequeños proyectos temáticos que incluyen tanto los contenidos conceptuales como los de procedimiento. El objetivo principal no ha sido la realización de un estudio sesgado de cada uno de estos ámbitos de las Ciencias Sociales, sino unirlos todos e interrelacionarlos de manera que el análisis, la interpretación y la posterior explicación sea un conjunto completo de todos ellos. La visión resultante será la suma de todos ellos y dará al alumnado una perspectiva que no se trabaja de forma habitual en las clases actuales de Geografía e Historia.

La puesta en práctica de la herramienta Google Earth en los grupos de secundaria se traduce, después de realizar este proyecto, en un aprendizaje más atractivo, visual y enormemente activo.

\section{MATERIAL ELABORADO PARA TRABAJAR EN EL AULA CON EL ALUMNADO}

Los objetivos pues han estado totalmente vinculados a la enseñanza-aprendizaje del currículo. Aquí señalaremos sólo algún ejemplo de las actividades desarrolladas con Google Earth para la consecución de los objetivos de este proyecto de investigación.

En estas actividades aparece señalado el grupo al que van dirigidas y el bloque temático desarrollado en cada una de ellas.

Como se ha reseñado más arriba, la manera de organizar el trabajo ha sido mediante mini proyectos que recogen los contenidos del currículo oficial pero presentados de una manera mucho más atractiva para el alumnado. De esta manera se consigue una mayor implicación tanto a la hora de conocer y valorar el uso de las TIC's, concretamente de Google Earth, como respecto de la visión de la Geografía.

Ejemplo de mini proyecto llevado al aula de $1^{\circ}$ y $3^{\circ}$ de ESO: 
Nivel: Primero o Segundo Ciclo de ESO

Curso: $1^{\circ}$ de ESO, $3^{\circ}$ de ESO

Área: Ciencias Sociales

Bloque temático II: Caracterización y distribución en el espacio de continentes, océanos, mares, unidades de relieve y ríos en el mundo, en Europa y en España. El relieve de los fondos oceánicos. El relieve de la Comunidad Valenciana ( $1^{\circ}$ de ESO); Bloque temático I: El relieve: marco físico de las actividades humanas. Las grandes unidades de relieve terrestre. El relieve, los ríos y las costas de Europa ( $3^{\circ}$ de ESO). El relieve de la Comunidad Valenciana.

Actividad: La Sierra de Aitana

OBJETIVO: Con esta actividad vamos a estudiar un sistema montañoso de la Comunidad Valenciana. Por ello vamos a analizar paso a paso su forma general, su aspecto y división en relación al lugar que hagamos mención (zona occidental de la montaña, central y oriental), formación, aprovechamiento económico, cumbres, valles, vegetación, clima...

Empezamos...

1. Partimos de la nuestra clase teórica del pasado lunes, donde hablamos qué es un sistema montañoso y de que existen en el mundo gran variedad de ellos. Por tanto suponemos que te ha quedado claro este CONCEPTO. Además, hemos visto que la Sierra de Aitana es una estructura montañosa de la provincia de Alicante. Puede ser que no lo sitúes en el espacio. Para ello comenzaremos buscando en el espacio Sierra de Aitana en el buscador de Google Earth o a través de coordenadas (Latitud y Longitud).

a. Poniendo en la parte de buscador las palabras Aitana, Sierra.

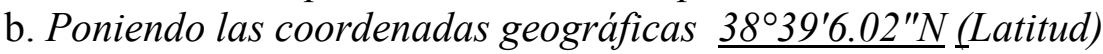

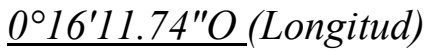

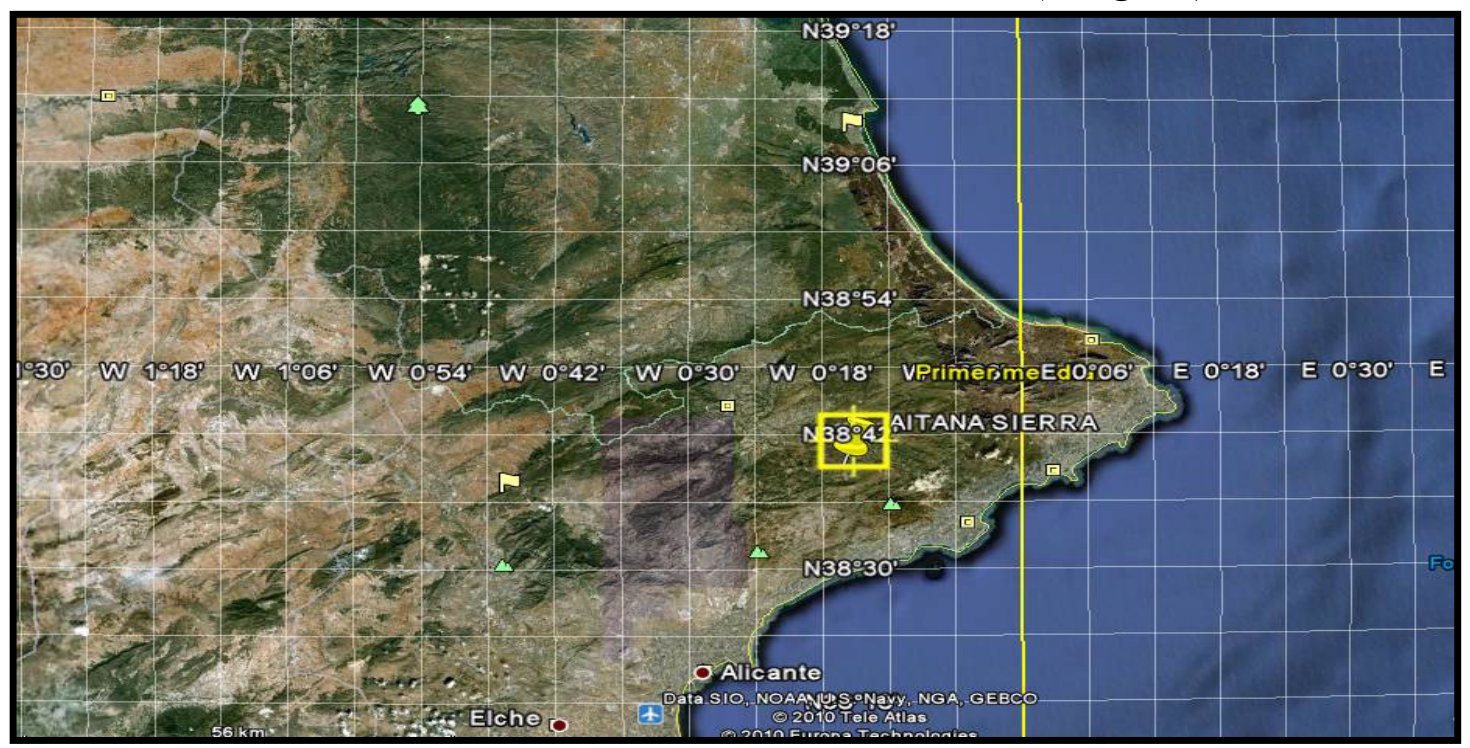

Figura 1. Localización y coordenadas de la Sierra de Aitana.

2. Vamos ahora a observar desde dónde hasta dónde se extiende esta sierra como conjunto. Para ello vaga por la zona una vez que hemos visto por qué lugar se extiende esta sierra. 


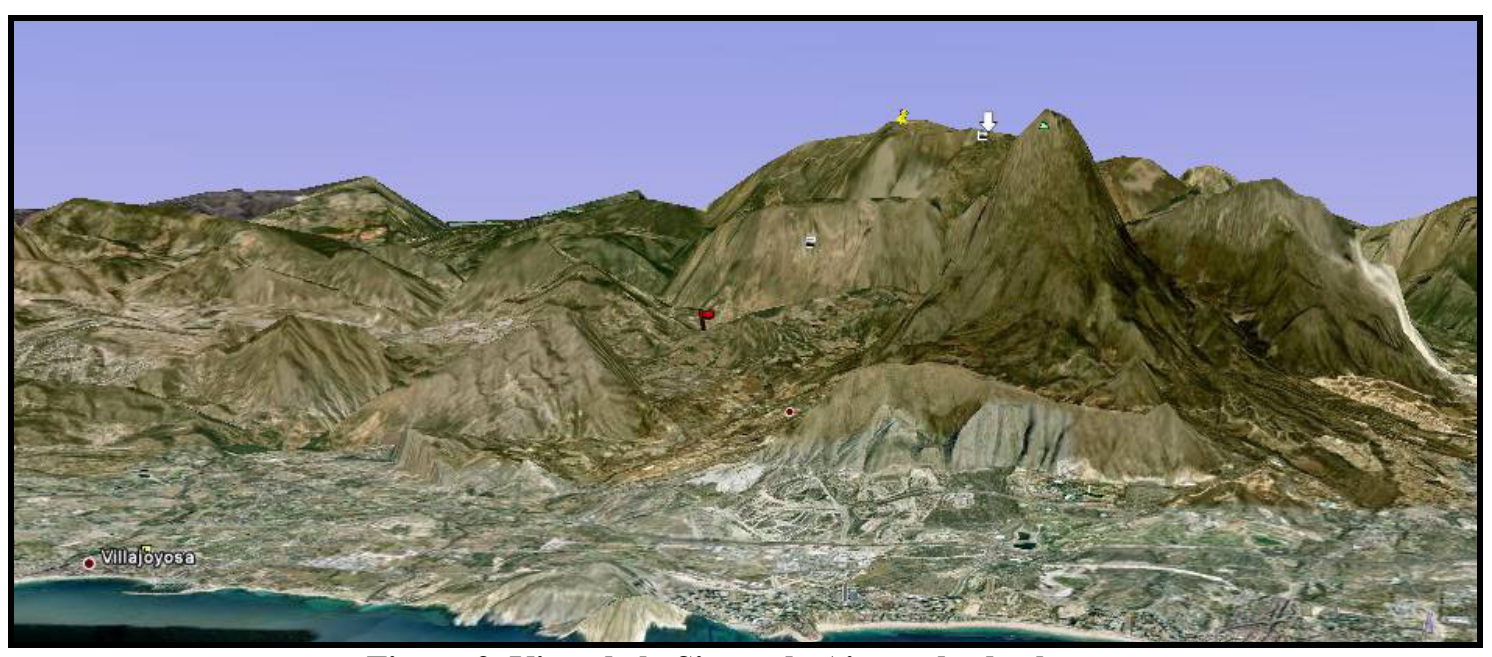

Figura 2. Vista de la Sierra de Aitana desde el mar.

3. Ya tienes una visión general de dónde está la sierra de Aitana dentro del conjunto de relieve de la provincia de Alicante y, aproximadamente por dónde se extiende. Vamos a trabajar este espacio. Esta actividad es aproximada, después ajustaremos.

a. Anota en este apartado por qué localidades podemos decir que "se extiende" la

Sierra de Aitana. Para ello vamos a ir colocando con marcas de posición

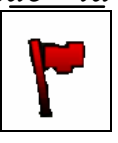
que sea una bandera de color rojo en cada una de estas localidades que pensamos atraviesan o están muy próximas a la Sierra de Aitana.

b. En CAPAS, señala FRONTERAS Y ETIQUETAS y marca sólo FRONTERAS DE ADMINISTRACIÓN DE $1^{\circ}$ ORDEN, NOMBRES DE ADMINISTRACIONES DE $1^{\circ}$ ORDEN y REGIONES ADMINISTRATIVAS. En la parte de ETIQUETAS, marca sólo LUGARES POBLADOS.

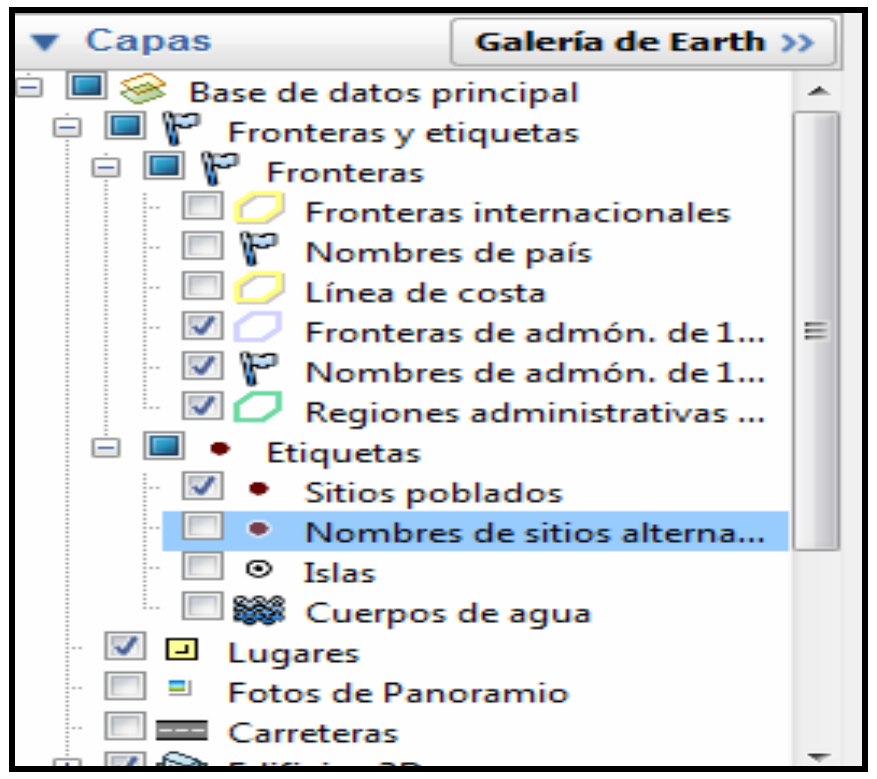

c. Ahora vamos a responder a las siguientes preguntas:

- ¿Por qué lugares crees que se extiende la Sierra de Aitana? 
- ¿Crees que estos lugares son todos de la provincia de Alicante?

d. Ahora vamos a hacer una pequeña ruta a "velocidad" para ver qué recorrido haríamos si viajáramos a lo largo de la Sierra de Aitana. Para ello ve situando una marca de posición $\beta$ en cada uno de los siguientes puntos: Alcolecha, Confrides, Benifato, Beniardá, Benimantell, Abdet, Guadalest, Sella.

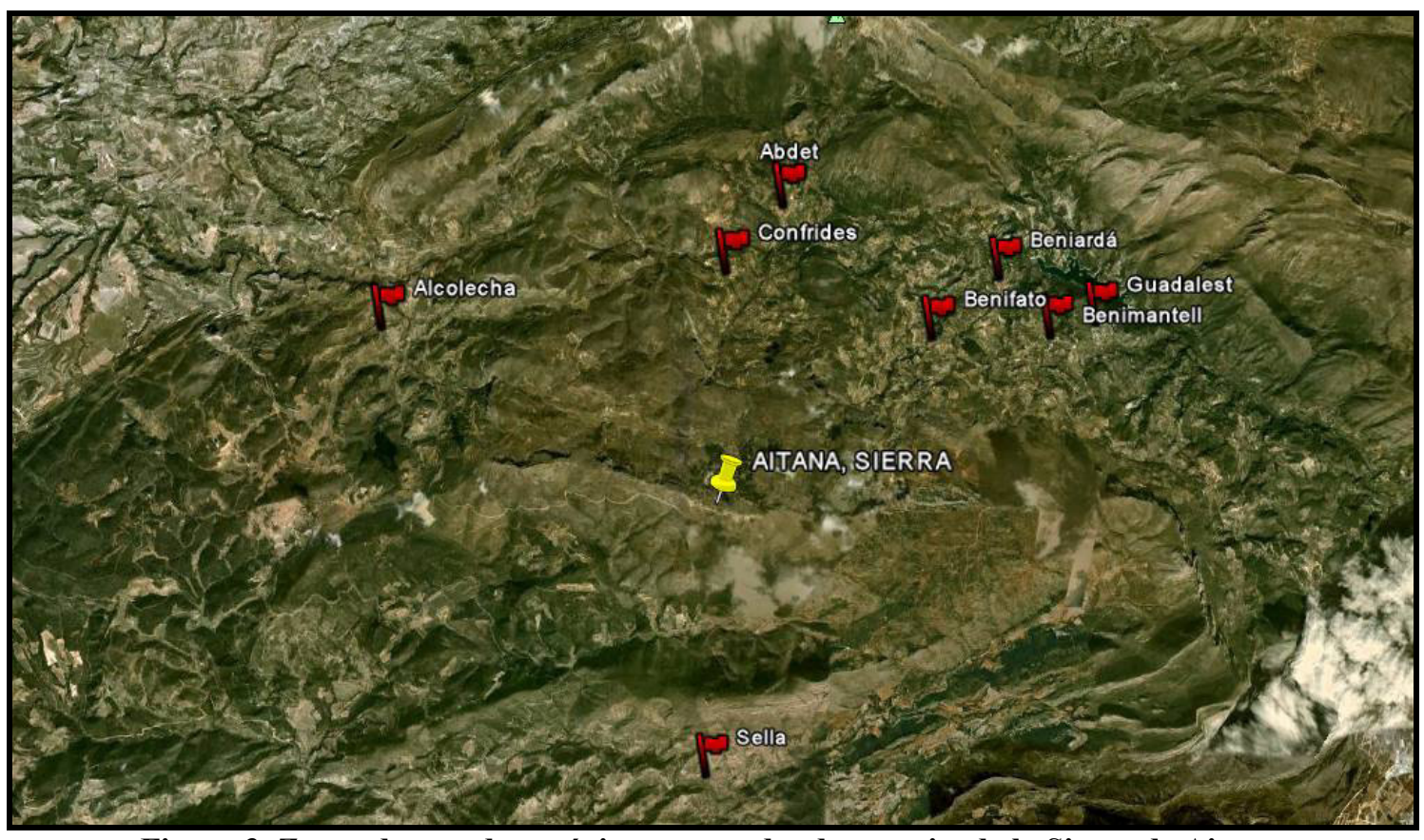

Figura 3. Zonas destacadas próximas o por donde se extiende la Sierra de Aitana

4. Para que esta actividad salga bien vamos, previamente vamos a localizar varios puntos en la siguiente dirección de de Internet: http://www.mapasespana.com/Mapa Provincia Alicante Comunidad Valenciana Espana.htm.

Como ves aquí te aparece un mapa de la provincia de Alicante. Ayudado por este "atlas" marca los siguientes lugares antes señalados. Con todo esto vamos a hacer una ruta.

A la hora de crear la ruta debemos hacerlo de la siguiente manera: HERRAMIENTAS/ OPCIONES/VIAJES/CUANDO SE CREA UN VIAJE DESDE UNA LÍNEA/ pondremos en ÁNGULO DE INCLINACIÓN DE LA CÁMARA $73^{\circ}$ y ALCANCE DE LA CÁMARA 5.000 metros. 


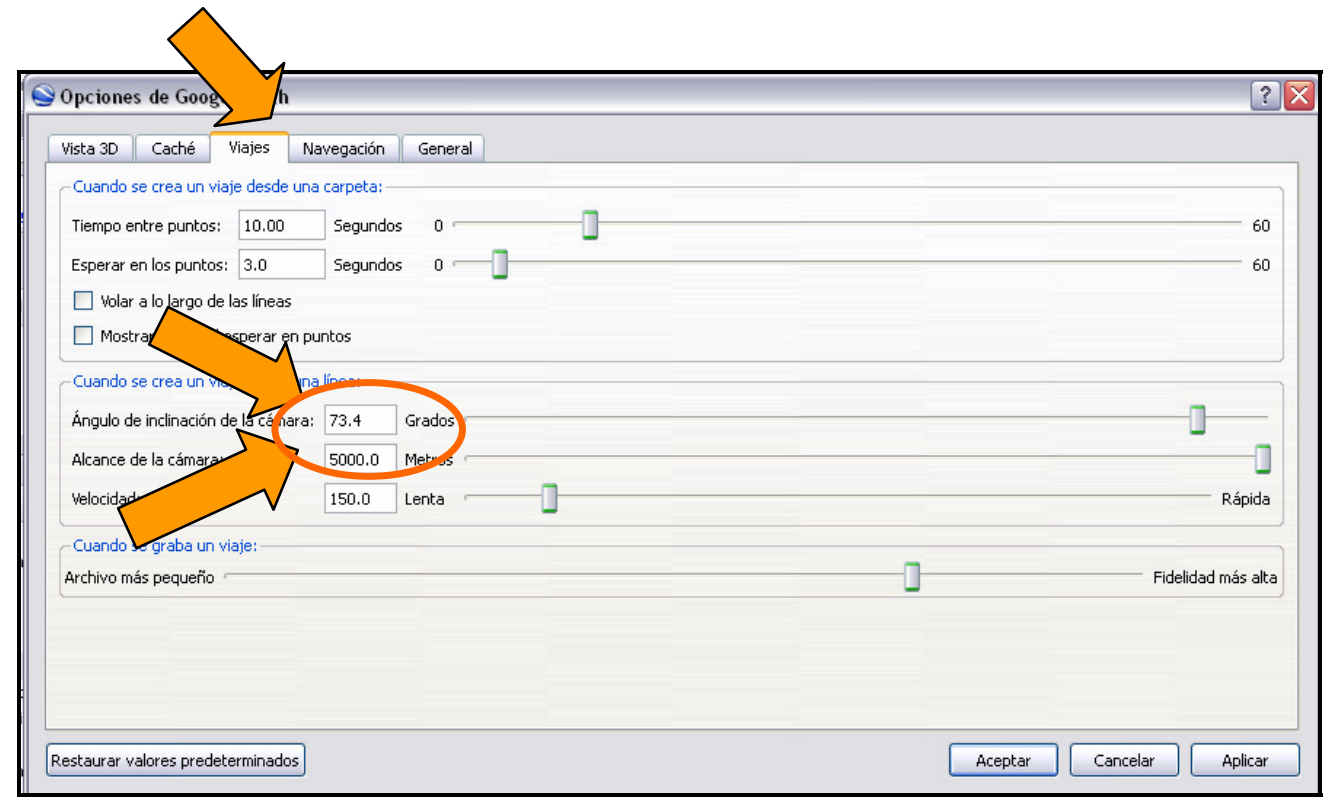

a. También tendremos en cuenta en CREAR RUTA los siguientes parámetros ALTITUD 1500 metros y el cuadro de la derecha en RELATIVA AL SUELO.

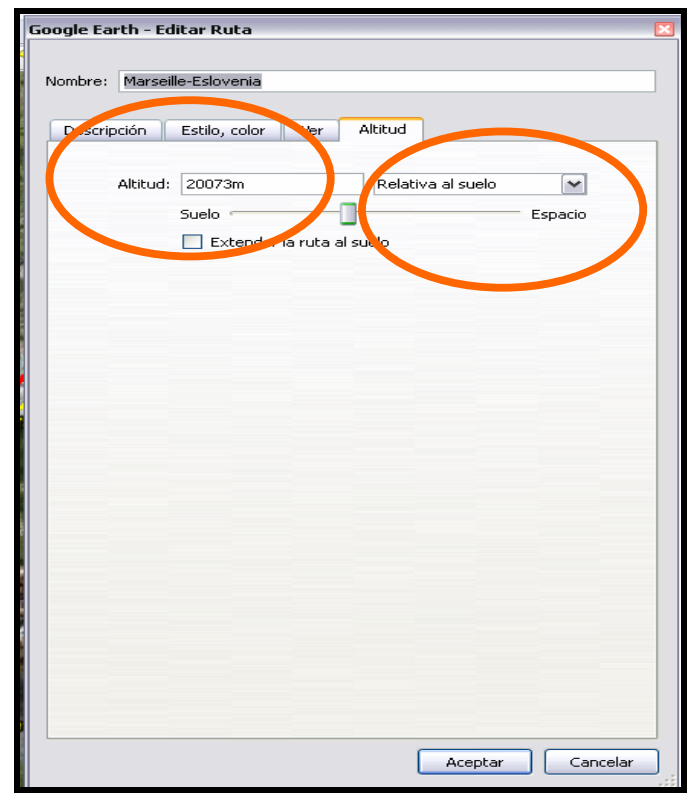

b. Como ya sabes cómo hacer una ruta sólo vamos a añadir de dificultad estos parámetros y que la línea sea de color ROJO y de una anchura de $5 \mathrm{~cm}$.

5.Vamos a trabajar ahora con esta ruta qué cambios se aprecian en el relieve desde la zona meridional (Sur) hasta la zona septentrional (Norte).

a. ¿Cómo crees que es el recorrido que hemos marcado ascendente o descendente?

b. Recordando el concepto de "montañas jóvenes" o poco erosionadas y "montañas viejas" o erosionadas ¿qué dirías que es la Sierra de Aitana, montañas jóvenes o viejas? Justifica tu respuesta con un ejemplo. Para ello sitúate en una zona de Aitana que consideres que cumple los requisitos para ser montaña joven o vieja. RECUERDA QUE 


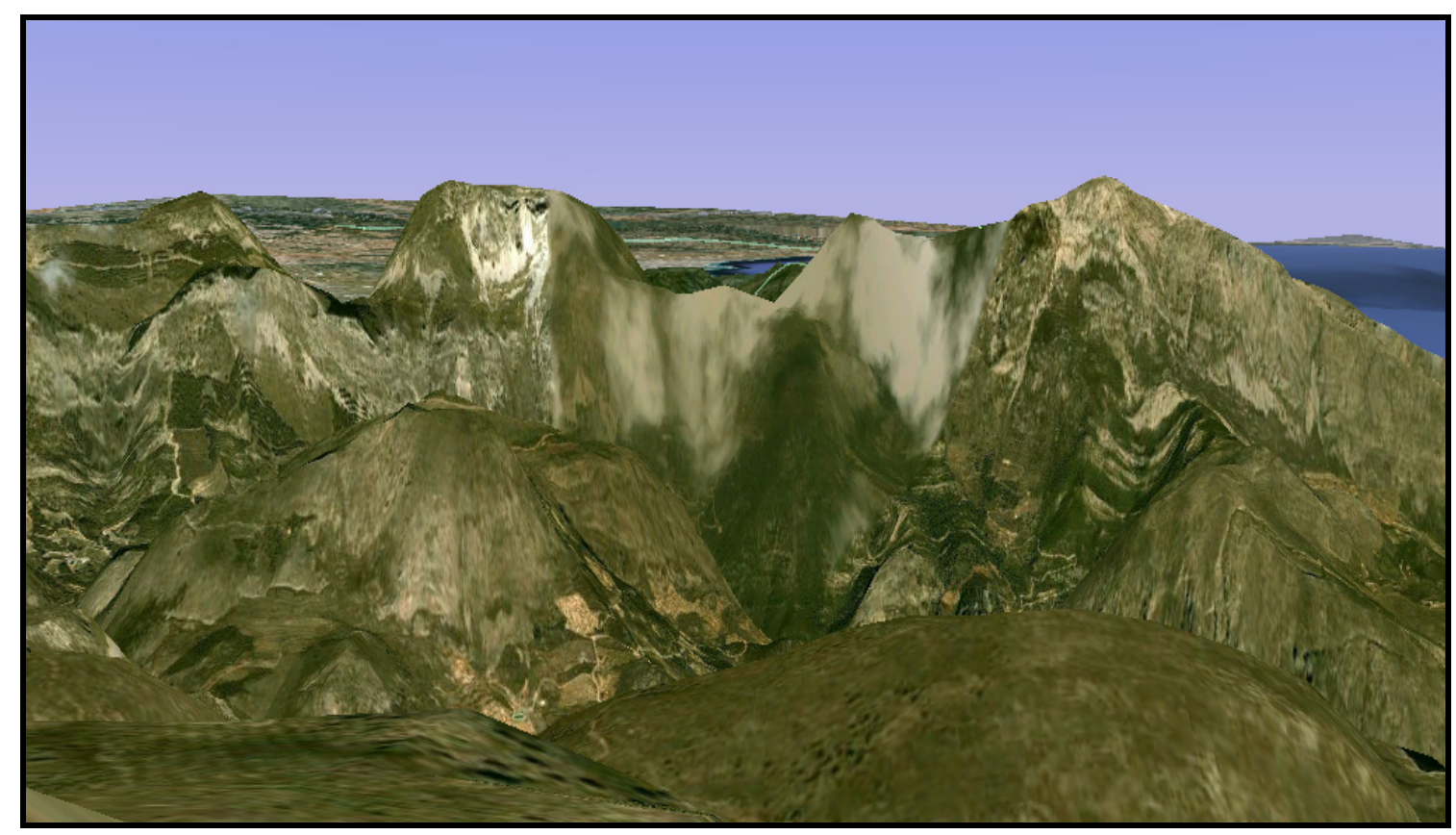

Figura 4. Vista de las zonas más elevadas de la Sierra de Aitana.

c. Sitúate en la cima más elevada que es el Pico de Aitana y di a qué altura se encuentra.

d. Después observa las características del espacio que rodea la CUMBRE del Pico de Aitana y describe a grandes rasgos qué ves (vegetación alta como árboles, vegetación baja como prados, no hay vegetación, hay nieve, etc.).

e. ¿Crees que la formación de la Sierra de Aitana será de hace poco o mucho tiempo? ¿Por qué?

f. Vamos a hacer una búsqueda "Macizo Galaico" en el buscador. Cuando lo encuentres haz una marca de posición en forma de flecha, $\checkmark$ de color naranja y con la identificación de MACIZO GALAICO también en color naranja. Ahora da una vuelta sobre este terreno y explica si aprecias diferencias respecto de esta estructura montañosa de la Sierra de Aitana ¿Cómo son las cumbres que ves en estás montañas? ¿Serán de formación reciente o no? ¿Por qué? 


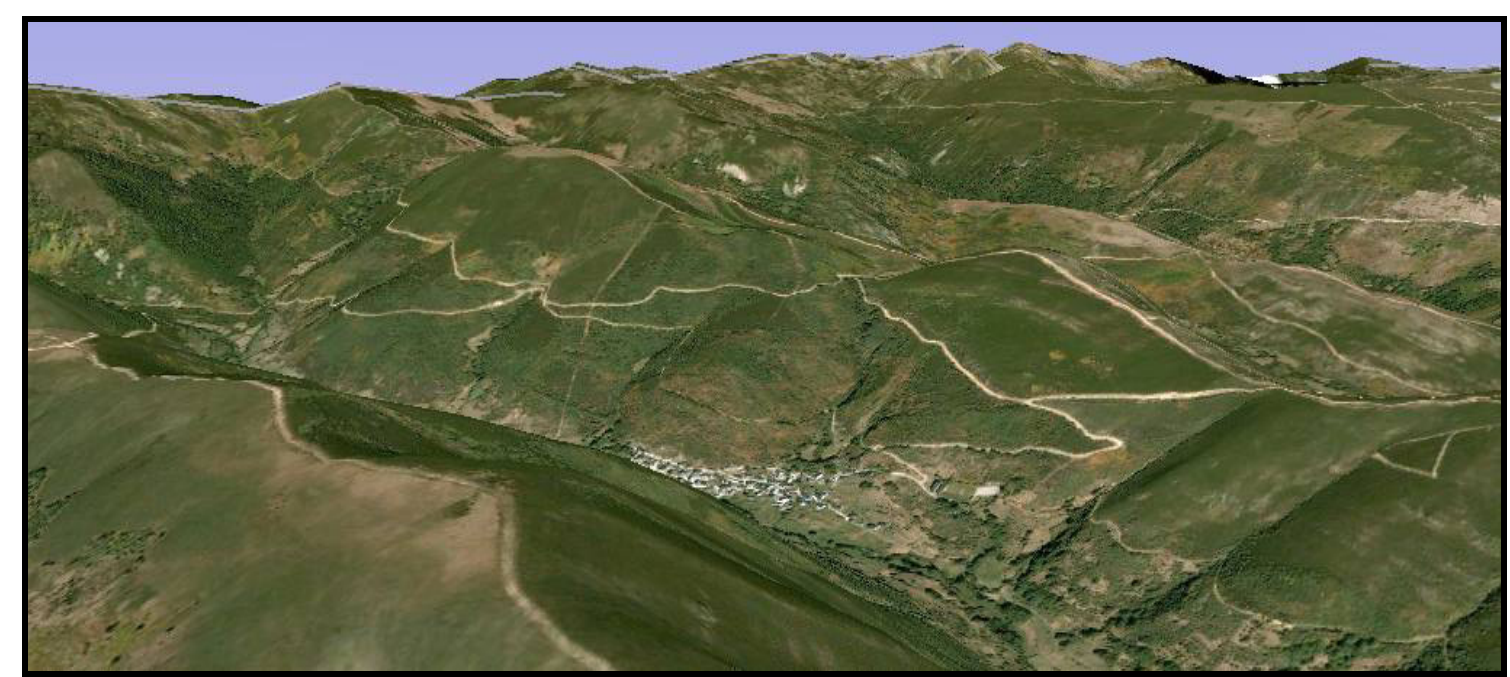

Figura 5. Macizo Galaico. Imagen panorámica.

6. Vamos a ir por una de las zonas más escarpadas (Pico de Aitana, Peña Alta, Peña Cacha, Peña Mulero) y vamos a buscar allí que, a través del viaje, observes qué es un valle, una cima, una depresión o cuenca, un altiplano o meseta, una llanura, golfo y una cordillera, CONCEPTOS ya estudiados en clases de Geografía.

a.Sigue en el Pico de Aitana y sitúate nuevamente en su cumbre. Ahora vamos a desplazarnos hasta otra zona.

b. En el buscador coloca las siguientes coordenadas: "38 $41^{\prime} 36.58^{\prime \prime} \mathrm{N}$ y $0^{\circ} 15^{\prime} 26.10^{\prime \prime} \mathrm{O}$ ".

c. Ahora crea una marca de posición en esta zona a la "altura del ojo" unos 460 $m$. de altitud. Es importante que hagas hincapié en estas vistas porque te permitirán entender OBSERVANDO, qué es un VALLE.

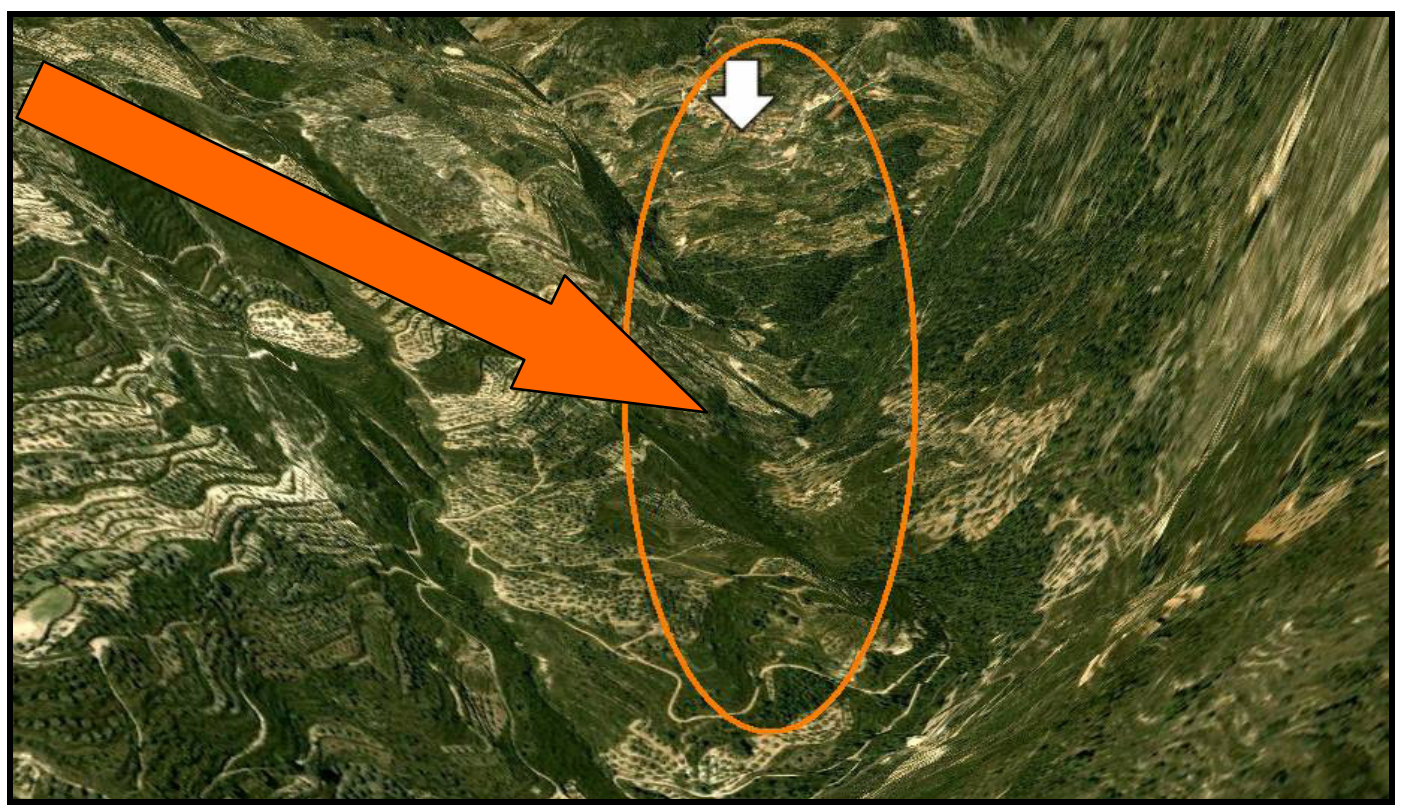

Figura 6: Valle de la zona de Guadalest, Sierra de Aitana. 
d. Una vez situado en dicho lugar gira sobre ti mismo para que averigües si te encuentras en una zona alta o llana.

A partir de esta actividad reconoces un valle. Reforcemos estos conocimientos haciendo un descenso, a partir de crear una ruta desde una zona elevada como Pico Aitana hasta una zona más llana, de unos $500 \mathrm{~m}$. de altitud.

e. Crearemos una ruta de descenso, desde la cumbre del Pico Aitana hasta la zona de Benimantell a $580 \mathrm{~m}$ de altitud. La ruta la vamos a hacer de color azul e intentaremos ir descendiendo de cumbre en cumbre hasta llegar a la zona más baja, a Benimantell. En este viaje cambiaremos los parámetro HERRAMIENTAS/ PROPIEDADES/ ÁNGULO DE INCLINACIÓN $30^{\circ} y$ ALCANCE DE LA CÁMARA EN 200 aproximadamente.

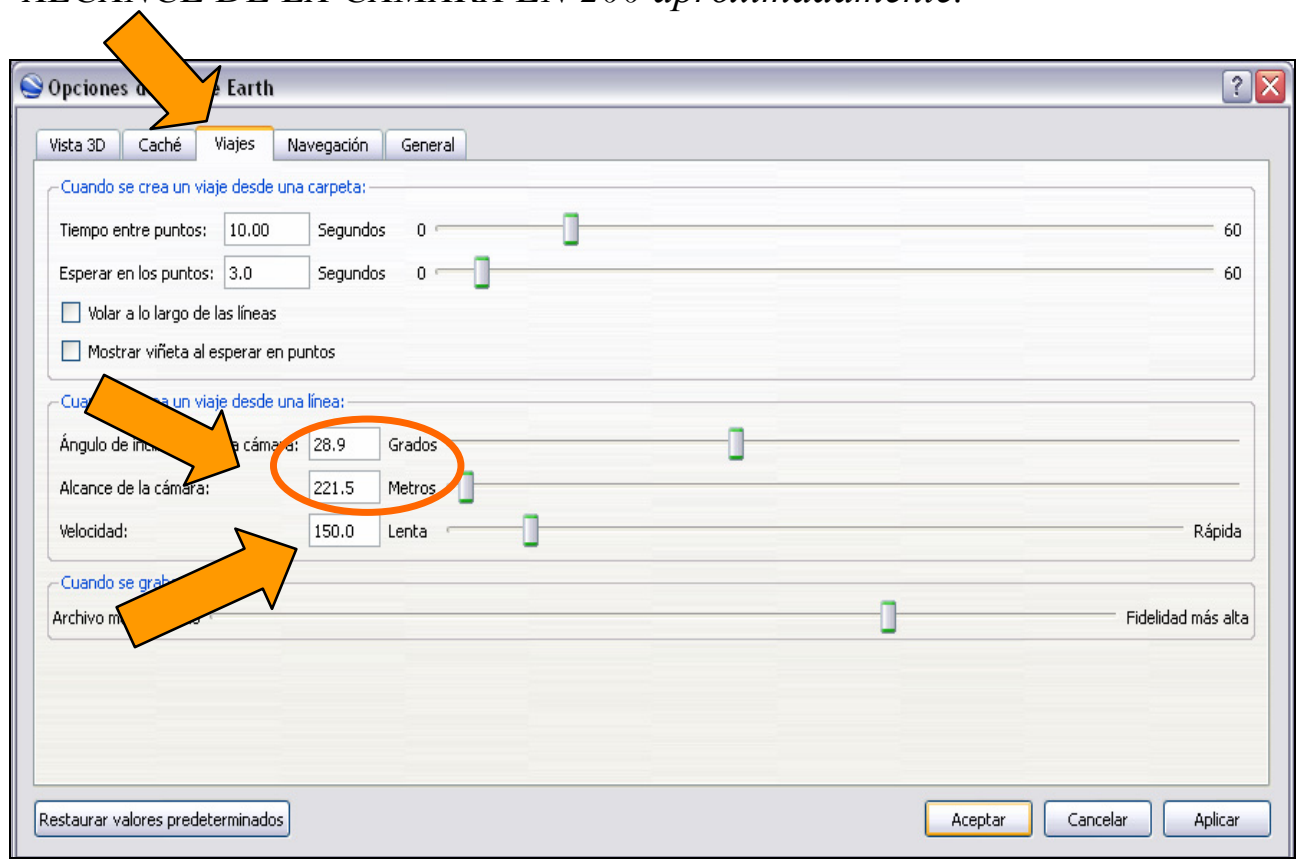

f. Vuelve sobre tu marca de posición de Valle y edita dicha marca de posición creando un texto donde se defina VALLE. Recuerda que la definición es mejor que la construyas tu mismo.

g. Ahora vamos a introducir la fotografía de un valle. Búscala en Internet y después añádela a la marca de posición que hemos hecho antes.

7. Sigue observando diferentes ejemplos de valle en la gran estructura de la Sierra de Aitana. Pero hemos estudiado, según su formación, en la clase teórica de la semana pasada, qué era un valle y qué forma podía tener según su origen.

Observemos un valle glaciar claramente en forma de "U".Para ello viajaremos a los Alpes Berneses. Ponte en marcha para una nueva actividad.

a.En el buscador vamos a localizar, dentro de la unidad de los Alpes, "Lauterbrunnen, Suiza".

b.Una vez sobre dicho lugar vamos a analizar este espacio. Para que lo observes bien gira sobre esta zona montañosa cuyo conjunto recibe el nombre de Alpes Berneses. 
c.Una vez que has dado una vuelta por esta zona y antes de comenzar a trabajar en Google, escribe en el buscador "Berna" y contesta a la siguiente pregunta inicial...

- ¿Por qué crees que a esta zona de los Alpes se les llama Alpes Berneses? FÁCIL VERDAD!!!!

- Ahora sitúate en las siguientes coordenadas geográficas

$$
\begin{gathered}
46^{\circ} 33^{\prime} 00.50 \text { '” } N \\
7^{\circ} 54^{\prime} 52.66^{\prime \prime} \mathrm{E}
\end{gathered}
$$

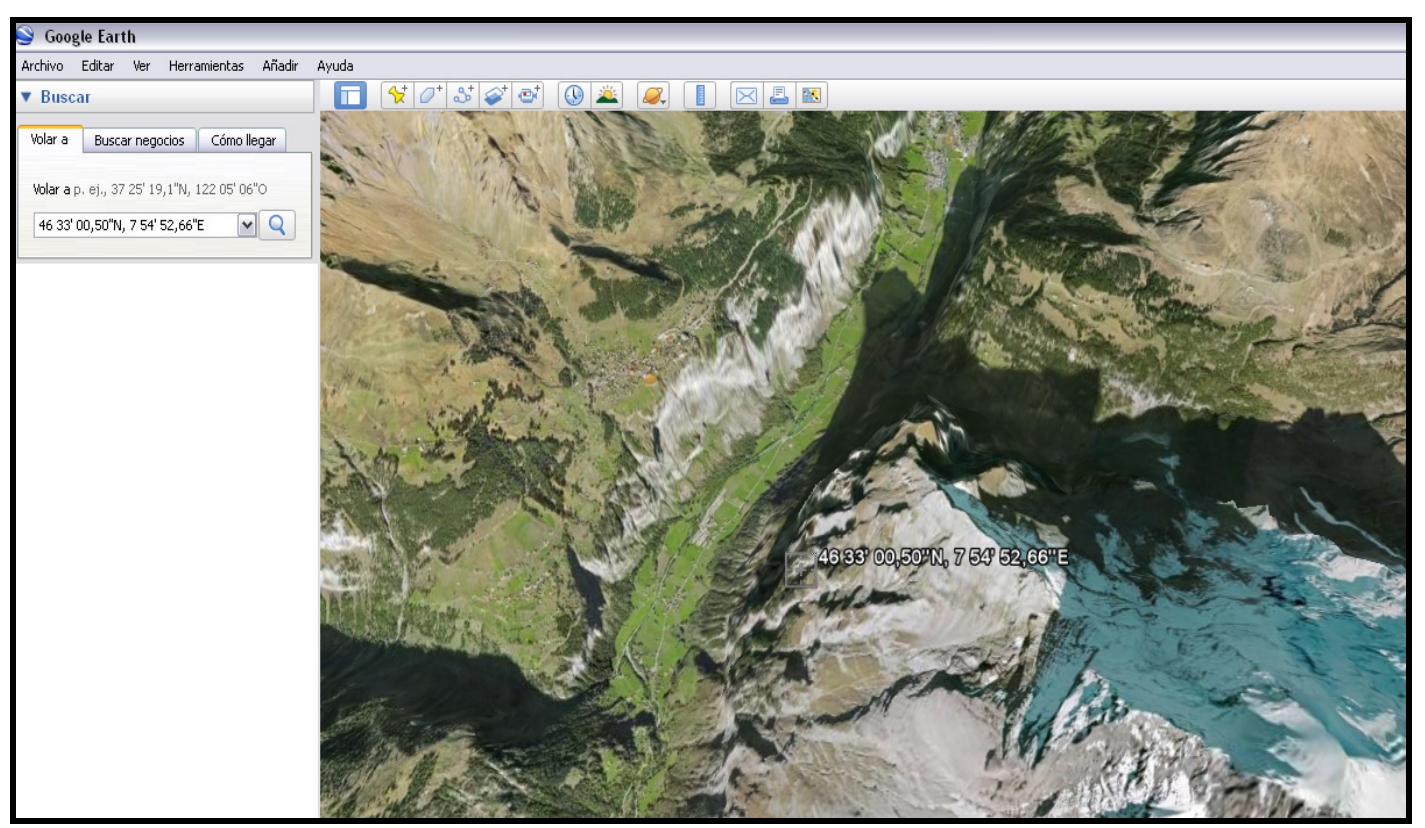

Figura 7. Valles Alpinos suizos

- En dichas coordenadas encontraras una forma parecida a la que hemos estado trabajando antes, en la Sierra de Aitana, pero con algo especial ¿observas diferencias? ¿qué tipo de diferencias?

- No te preocupes si ves todos los paisajes igual...vamos a ir poco a poco, para ello observa exactamente qué forma tienen las paredes de los valles que ves en estás coordenadas ¿son pareces escarpadas que caen bastante rectas al suelo o caen en diagonal?

- Ahora vamos a poner una marca de posición en las coordenadas geográficas que hemos buscado. En dicha marca de posición recuerda que debes escribir que se trata de un valle glaciar. En descripción busca un enlace de Internet y añádelo junto con una fotografía de un valle glaciar. 


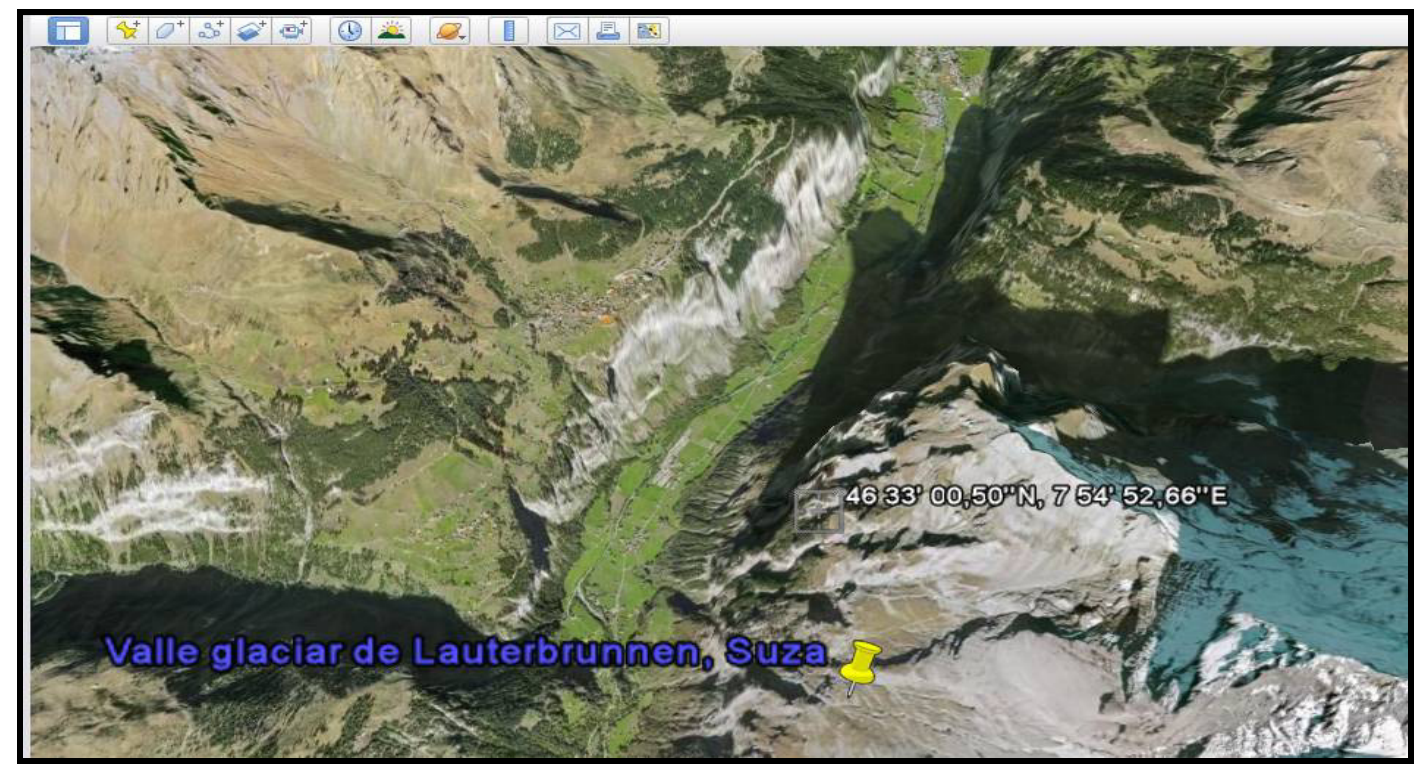

Figura 8. Valle glaciar de Lauterbrunnen, Suiza

Puede ser que te resulte complicado diferenciar los distintos tipos de valle. Para ayudarte hemos guardado en mis imágenes de tu ordenador fotografía de tipos de valles. Si quieres puedes recurrir a ellas para terminar de entender las formas distintas que estas estructuras presentan, ÁNIMO.

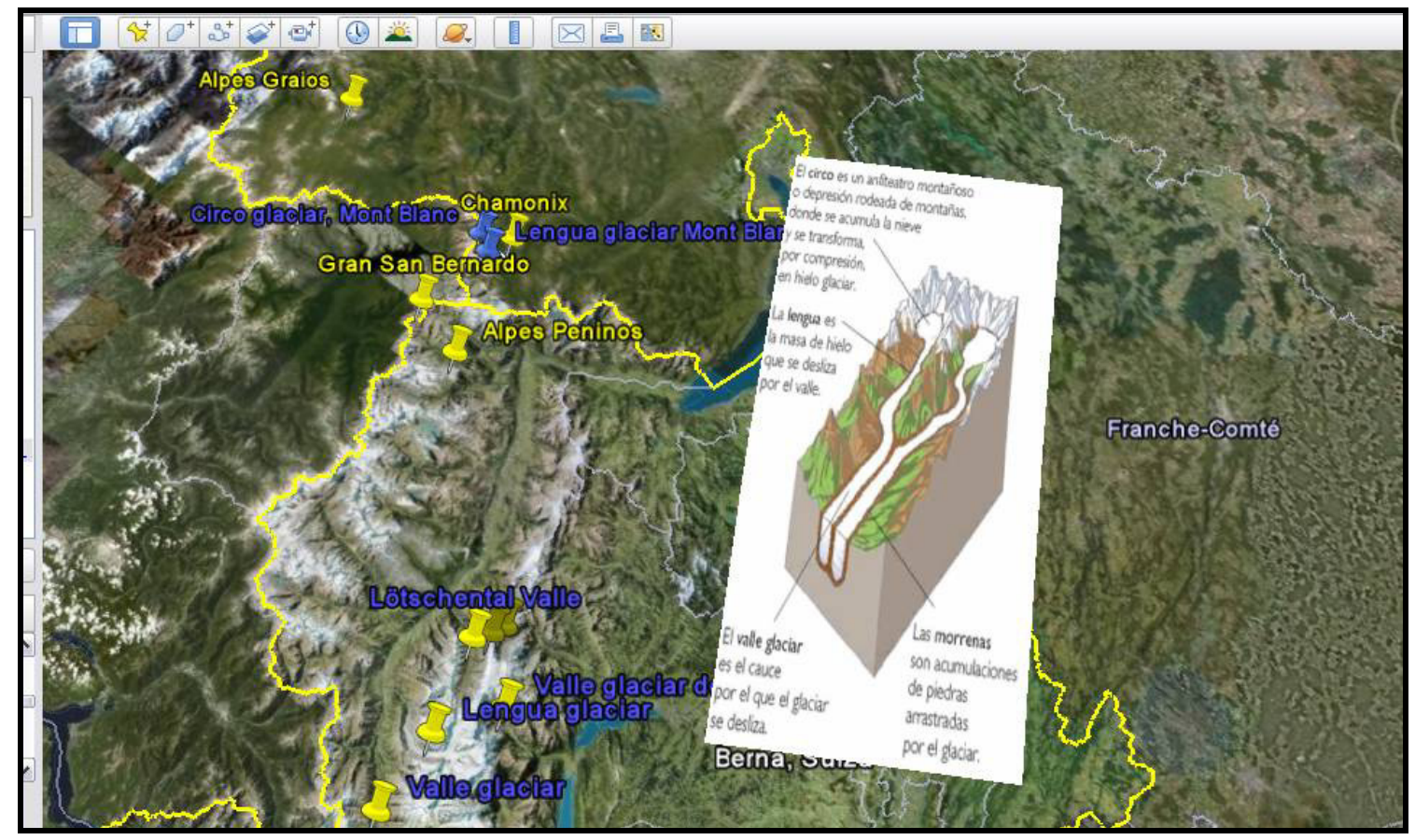

Figura 9. Superposición de la imagen-esquema de un valle.

8. La economía de esta zona también es un tema importante a la hora de estudiar la Sierra de Aitana. Dentro de la economía vamos a ver cómo son las comunicaciones en esta zona concreta de la provincia de Alicante.

a. Vamos a observar en la zona de la Sierra las vías de comunicación que existen. En CAPAS activa CARRETERAS. 
b. Activamos en CAPAS/LUGARES DE INTERÉS/TRANSPORTES sólo, FERROCARRIL, FLUVIAL, FERROCARRIL DE MONTAÑA.
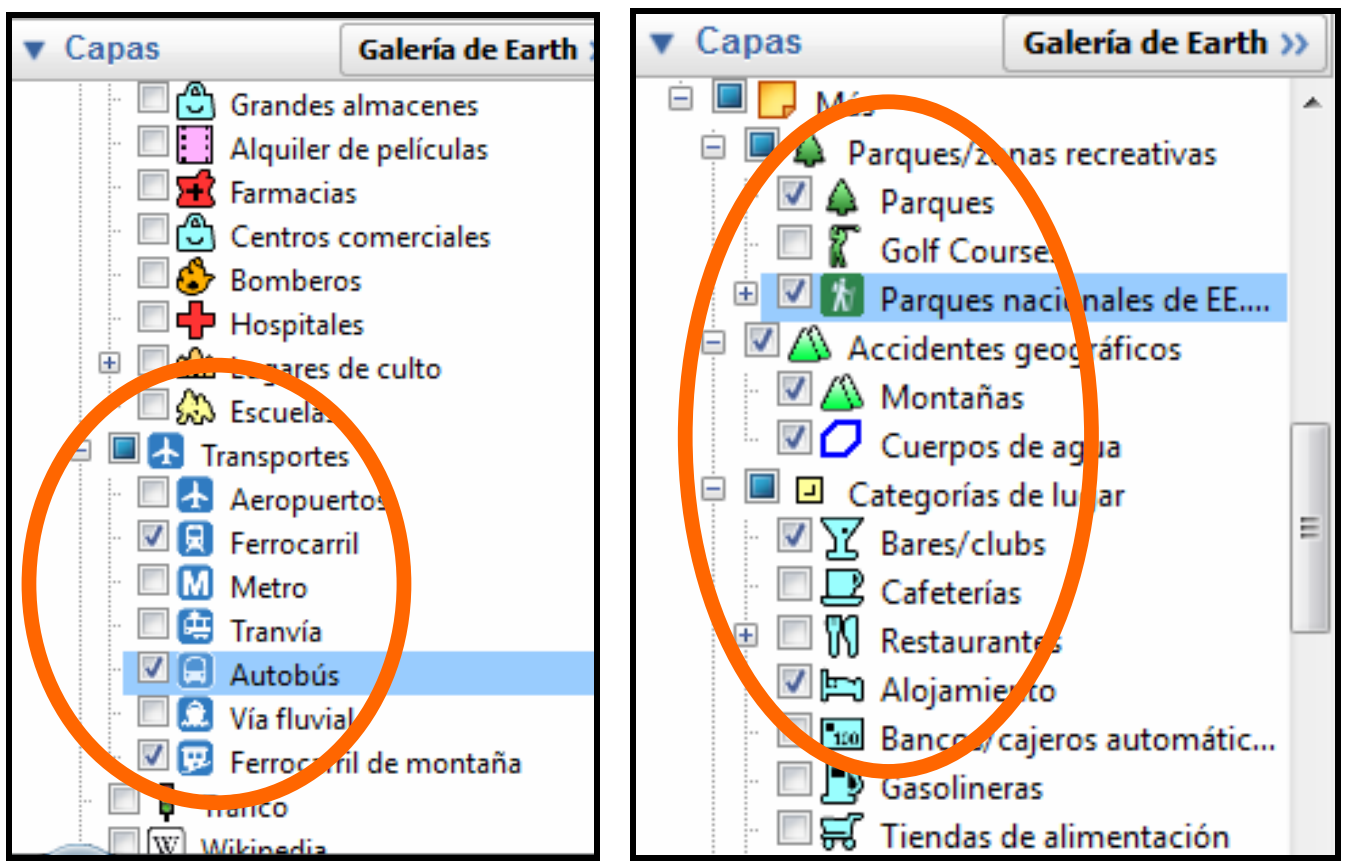

c. ¿En general crees que la zona de la Sierra de Aitana se encuentra bien comunicada con otros lugares cercanos?

d. Ahora vamos a activar también en FRONTERAS/SITIOS POBLADOS ¿crees que las comunicaciones entre poblaciones cercanas son buenas? ¿limitaran de alguna manera la economía este sistema de comunicaciones?

e. Vamos a activar en CAPAS/ PARQUES, MONTAÑAS, PARQUES NACIONALES DE EE., ALOJAMIENTOS (Turismo rural) para ver alguna de las características de la posibilidad que ofrece este entorno montañoso. Para ser más conscientes de ello y, a pesar de que hemos visto la cumbre de alguna de las montañas, vamos a buscar un climograma que insertaremos como imagen.

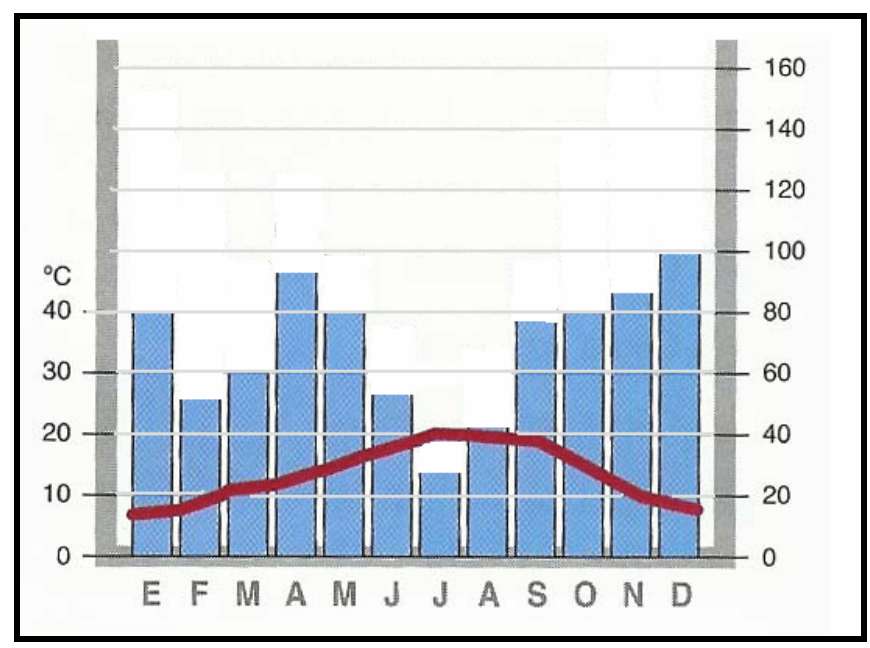


*También podemos utilizar el Excel para elaborar nuestros propios climogramas. Para ello buscamos los datos de temperaturas $\left(\mathrm{T}^{\circ} \mathrm{C}\right)$ y precipitaciones $(\mathrm{Pp} \mathrm{mm}$ ) que encontraremos en cada una de las localidades por donde atraviesa la Sierra de Aitana.

- Nos interesa relacionar la situación espacial de la Sierra de Aitana con el apartado de climas estudiado en nuestras clases teóricas. Para ello vamos a activar algunas de las herramientas de Google Earth para poder diferenciar en lugar de MERIDIANOS y PARALELOS (LATITUD y LONGITUD) qué tipo de clima encontraremos a lo largo de la Sierra.

a. Para hacer aparecer los meridianos y paralelos activamos en VER/CUADRÍCULA.

b. Sobre esta cuadrícula vamos a fijarnos a qué distancia nos encontramos del trópico de Cáncer y de los círculos polares. También el meridiano de Greenwich.

c. También nos permite ver si nos encontramos situados en longitud $E u \mathrm{~W}$.

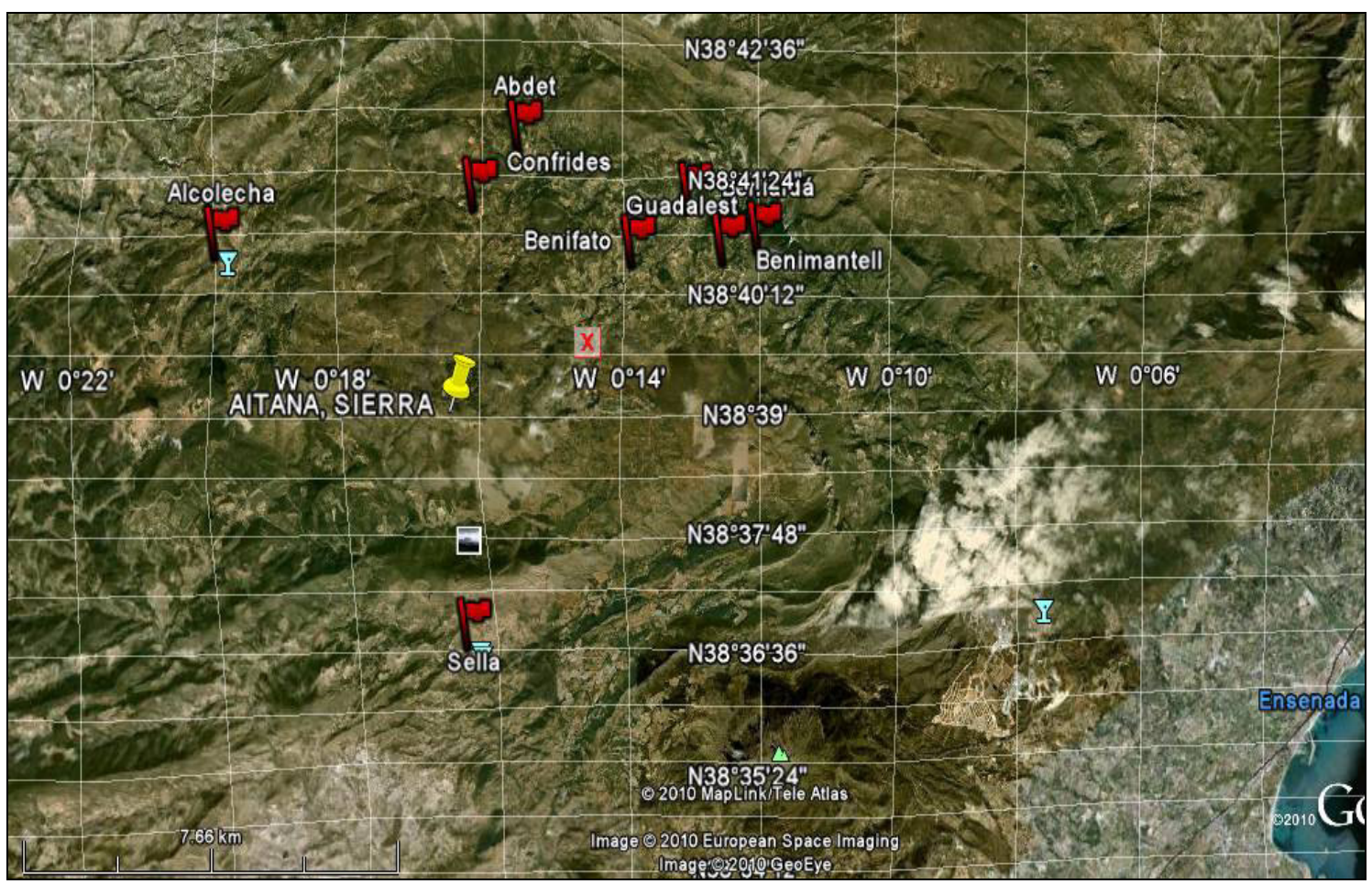

Figura 10. Meridianos y paralelos con en la Sierra de Aitana.

9. Por último analizaremos la organización de la población en el espacio. Para ello nos fijaremos en la cantidad de pequeñas, medianas y grandes poblaciones que existen JUSTO en la zona que estamos estudiando. Recuerda que en clase, hemos analizado los distintos tipos de poblamiento. Es ahora el momento de demostrar que has entendido dichos conceptos, ÁNIMO.

a.Para observar las características del poblamiento debemos tener marcado en CAPAS/FRONTERAS/FRONTERAS DE ADMÓN. 1er; NOMBRES DE ADMÓN. ler; SITIOS POBLADOS, NOMBRES DE SITIOS ALTERNATIVOS.

b.Vamos a observar con atención si abundan las poblaciones grandes, medianas o pequeñas en las localidades que hemos señalado en actividades anteriores. 
c. ¿Qué tipo de poblaciones crees que son? Fíjate en las zonas de los VALLES y en los lugares donde hay alojamientos (seguramente casas rurales) y restaurantes, zonas de parques naturales o lugares de interés paisajístico, porque pueden ayudarte a entender el tipo de poblamiento.

d.¿Crees que será una economía basada en la actividad industrial? ¿Por qué?

e.Explica con tus palabras si existe relación entre la orografía (relieve montañoso o no que estamos estudiando) con el tipo de poblamiento y con la economía que pueda desarrollarse allí.

\section{RESULTADOS ESPERADOS Y LOGRADOS}

Cuando se diseñó este proyecto de investigación se pensó en conseguir que el alumnado alcanzara los contenidos que, para cada nivel, marca el currículo oficial de la Generalitat Valenciana, para el área de Ciencias Sociales. También se esperaba que el alumnado aprendiera el manejo de la herramienta informática, Google Earth.

Como se puede comprobar en las evaluaciones realizadas a los alumnos de los diferentes niveles, se han alcanzado los mínimos marcados por ley para el área de Ciencias Sociales y, de manera concreta, los contenidos geográficos que se han trabajado con Google Earth.

La evaluación del alumnado, a través de pruebas escritas (soporte papel e informático) y orales ha sido positiva. Se muestra aquí un tipo de prueba realizada a alumnado de $1^{\circ}$ de ESO relacionada con la evaluación de contenidos (conceptuales y procedimentales) tales como: escala gráfica, escala numérica, meridiano, paralelo, coordenadas geográficas, latitud, longitud, unidades de medición de las coordenadas (grados, minutos y segundos), etc. A partir de este ejercicio práctico, trabajado en el aula de Informática, se ha pretendido que el alumnado demuestre que entiende y comprende los conceptos de escala, latitud y longitud (por extensión meridiano y paralelo); que sepa averiguar la distancia entre dos puntos a partir de la escala gráfica (contenido procedimental); que asimile la importancia de estos contenidos (conceptuales y procedimentales) no solo para las clases de Geografía sino también para su vida diaria; que comprenda que lo que estudia en clase de Geografía es útil para él o ella; que "cambie" su opinión sobre las Ciencias Sociales y deje de considerarlas algo teórico, fuera de lugar, no relacionado con lo que ocurre a diario e inservible. 


\section{PRUEBA ESCALAS $1^{\circ}$ ESO}

Nombre:

Curso:

Fecha:

\section{EJERCICIOS DE ESCALA.}

Para realizar esta actividad tienes dos sesiones de 55' cada una de ellas. Recuerda que todo lo que hagas queda guardado en Mis Lugares Temporales $\mathrm{y}$, después, debes guardarlo en tu CD de trabajo para ser evaluado.

Vamos a hacer un ejercicio con Google Earth para comprobar si has aprendido algunos conceptos trabajados en el aula de Ciencias Sociales y también de Informática. El tema a trabajar será la escala, ¿RECUERDAS?

\section{NORMAS ANTES DE EMPEZAR:}

Activamos "Leyenda de escala" en el menú "Ver", podemos llevar a la práctica la cuestión planteada de escala gráfica, pero con fotos de satélite.

Recuerda también que existen ciertas funciones en nuestra herramienta Google Earth que te van a permitir razonar qué es la escala gráfica. Empezamos...

Con la ayuda de la escala gráfica, una regla y una calculadora, calcula la distancia que hay en línea recta desde tu casa a la puerta del instituto.
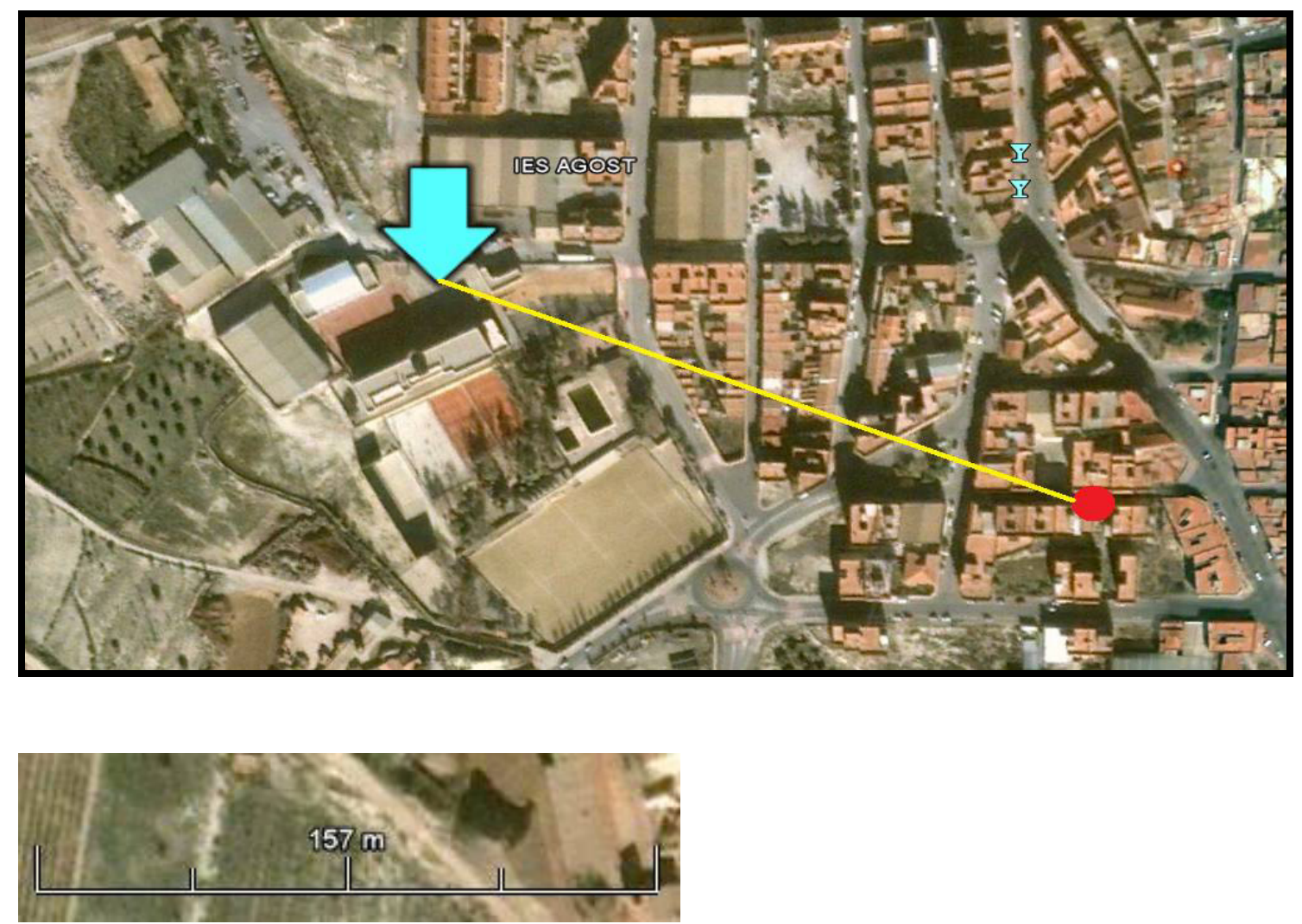


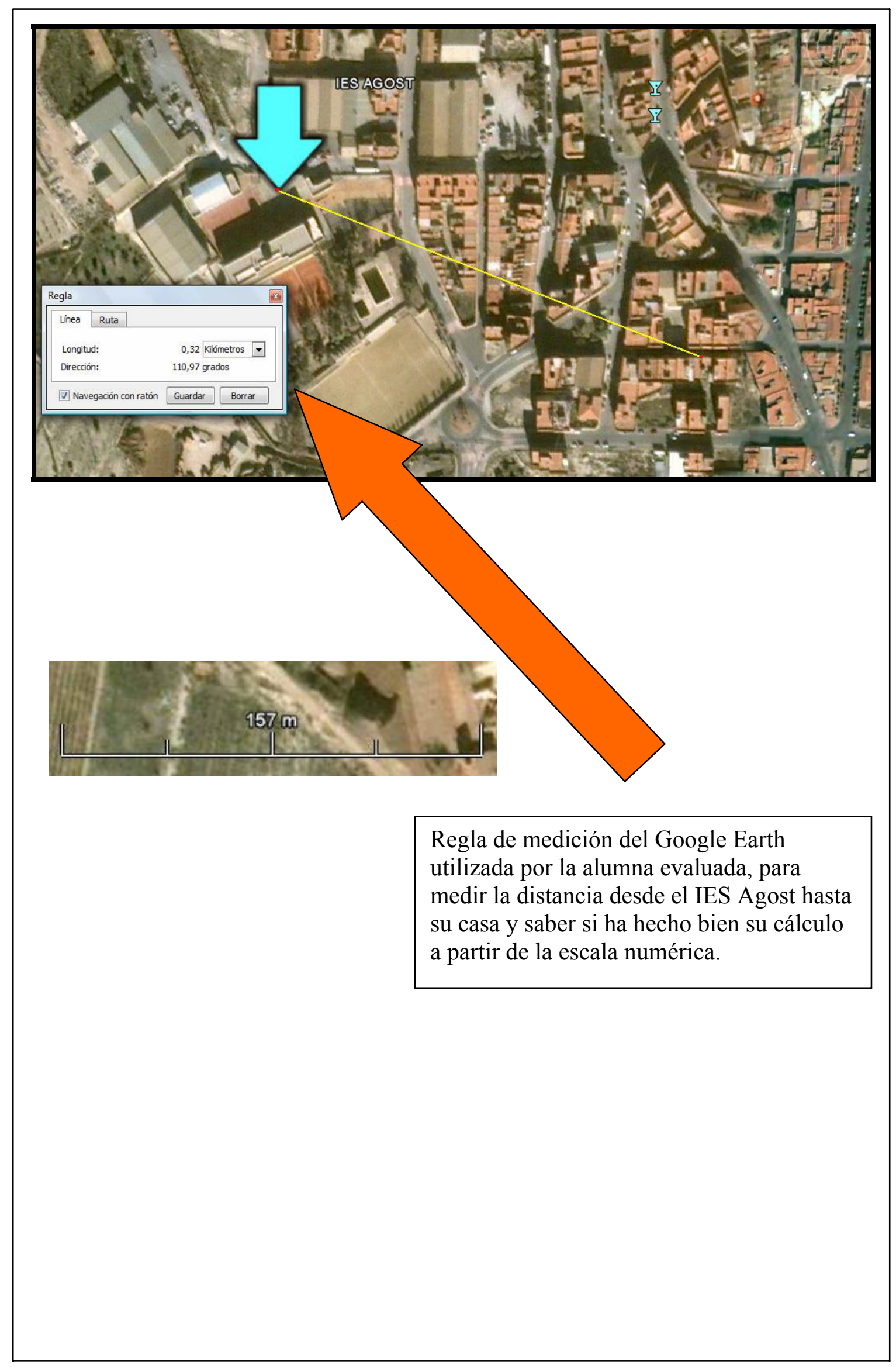


En porcentajes, los resultados de los exámenes han sido los siguientes, por curso y por evaluación:

\begin{tabular}{|c|c|c|c|c|c|c|c|}
\hline \multicolumn{7}{|c|}{ Resultados de la evaluación del alumnado (\%) } \\
\hline $\begin{array}{c}\text { EVALUACIÓN } \\
/\end{array}$ & $1^{\circ}$ ESO A & $1^{\circ}$ ESO B & $2^{\circ}$ ESO A & $2^{\circ}$ ESO B & $3^{\circ}$ ESO A & $3^{\circ}$ ESO B & $2^{\mathbf{0}}$ BACH \\
\hline $1^{\mathbf{0}}$ Evaluación & $\begin{array}{c}100 \% \\
\text { aprobados }\end{array}$ & $\begin{array}{c}95 \% \\
\text { aprobados }\end{array}$ & $\begin{array}{c}75 \% \\
\text { aprobados }\end{array}$ & $\begin{array}{c}74 \% \\
\text { aprobados }\end{array}$ & $\begin{array}{c}95 \% \\
\text { aprobados }\end{array}$ & $\begin{array}{c}90 \% \\
\text { aprobados }\end{array}$ & $\begin{array}{c}90 \% \\
\text { aprobados }\end{array}$ \\
\hline $2^{\mathbf{0}}$ Evaluación & $\begin{array}{c}95 \% \\
\text { aprobados }\end{array}$ & $\begin{array}{c}85 \% \\
\text { aprobados }\end{array}$ & $\begin{array}{c}82 \% \\
\text { aprobados }\end{array}$ & $\begin{array}{c}76 \% \\
\text { aprobados }\end{array}$ & $\begin{array}{c}90 \% \\
\text { aprobados }\end{array}$ & $\begin{array}{c}91 \% \\
\text { aprobados }\end{array}$ & $\begin{array}{c}87 \% \\
\text { aprobados }\end{array}$ \\
\hline $3^{\mathbf{0}}$ Evaluación & $\begin{array}{c}100 \% \\
\text { aprobados }\end{array}$ & $\begin{array}{c}98 \% \\
\text { aprobados }\end{array}$ & $\begin{array}{c}90 \% \\
\text { aprobados }\end{array}$ & $\begin{array}{c}75 \% \\
\text { aprobados }\end{array}$ & $\begin{array}{c}97 \% \\
\text { aprobados }\end{array}$ & $\begin{array}{c}91 \% \\
\text { aprobados }\end{array}$ & $\begin{array}{c}93 \% \\
\text { aprobados }\end{array}$ \\
\hline
\end{tabular}

Fuente: Elaboración propia a partir de los resultados obtenidos con el proyecto realizado.

\section{EVALUACIÓN FINAL DEL PROYECTO}

\section{Evaluación del proceso}

Esta parte de la evaluación del proyecto desarrollado, se ha realizado a lo largo de la puesta en marcha en el aula. Merece la pena destacar que la adecuación de los contenidos trabajados con los objetivos perseguidos y la temporalización marcada han sido los correctos. De esta manera no han aparecido problemas importantes en cuanto al proceso y desarrollo del proyecto. Simplemente volver a señalar que algunas sesiones que debían hacerse en el aula de Informática se han impartido en la clase de Ciencias Sociales, utilizando como medio el cañón del departamento de Geografía e Historia y las pantallas del centro. Por tanto, la valoración del proceso se da por conseguida y es positiva.

\section{Evaluación de los resultados}

La evaluación de los resultados ha sido muy satisfactoria en tanto en cuanto se han alcanzados los objetivos marcados y también se han conseguido los contenidos propuestos por el currículo de enseñanza secundaria de la Comunidad Valenciana. Los porcentajes de aprobados han superado la media de otros cursos y se ha observado que el área de Geografía se afronta, por el alumnado, con "otros ojos" mucho más positivos y activos. En lugar de "alejarse" de este tipo de actividades (mini proyectos) la implicación del alumnado ha sido mayor. La participación ha sido total y ello se confirma en los resultados obtenidos en los exámenes realizados.

Se han comparado los resultados de las pruebas iniciales y los obtenidos al final de curso con la agradable cuantificación de que se han adquirido tanto contenidos conceptuales como relacionados con los procedimientos y actitudes hacia el área de Geografía. Por tanto, la evaluación de los resultados es muy satisfactoria. 


\section{Evaluación del material y la metodología}

La valoración del material diseñando (mini proyectos) ha sido también positiva en cuanto a que ha conseguido los objetivos curriculares marcados al inicio del trabajo y, lo más importante, la combinación de teoría y praxis. Las clases han sido enormemente dinámicas con la participación del 100\% del grupo en la resolución de dudas, puesta en común de los "descubrimientos" logrados con el uso de Google Earth, análisis de elementos geográficos físicos y humanos como si se tratara de un trabajo de campo en vivo y en directo.

Ante todo se destaca que, como ya se comentó más arriba, Google Earth ha permitido al alumnado de un instituto de Alicante estudiar, comprender, analizar, reconocer y entender conceptos geográficos que, sin la observación directa sobre el terreno, son difíciles de asimilar. Así pues entendemos que Google Earth es una herramienta positiva para el desarrollo de los contenidos y objetivos del currículo de Ciencias Sociales. Es un instrumento, dentro de las nuevas tecnologías, indispensable para llevar el "espacio geográfico" al aula.

En referencia a la metodología utilizada, los mini proyectos, también han tenido una acogida y valoración positiva por parte del alumnado y del profesorado. Poder trabajar distintos aspectos de la geografía al unísono permite obtener una visión general y mucho más real que los sistemas tradicionales de estudio. Trabajar, a través del mini proyecto, cómo afecta la latitud al clima, al relieve, cómo condiciona parcialmente el tipo de aprovechamiento agrícola, cómo es posible superar ese medio con las nuevas tecnologías (irrigación artificial), por qué lugares discurre el Segura y el Vinalopó, cómo afecta una elevación del terreno como la Sierra de Aitana a las comunidades cercanas...en resumen analizar y entender, de manera conjunta y no aislada, los aspectos geográficos ha permitido al alumnado comprender que la materia Geografía no es un área teórica y abstracta sino que está impregnada de la realidad cotidiana y nos afecta a todos. Es una ciencia viva y en constante evolución, que se adapta a los cambios y que nos empuja, como geógrafos educadores a crecer y evolucionar con ella.

\section{CONCLUSIONES}

Las conclusiones alcanzadas al final de la realización del proyecto de trabajo con Google Earth son las siguientes:

- Las nuevas tecnologías aparecen como las nuevas herramientas a utilizar por parte del profesorado de educación secundaria obligatoria (y también de otros niveles superiores e inferiores) pues proporcionan otra dimensión a la enseñanza más acorde con el mundo en el que vivimos tecnificado y en constante evolución.

- Dentro de las nuevas tecnologías (TIC's), Google Earth es una herramienta para la enseñanza de las Ciencias Sociales (Geografía e Historia) puesto que permite acercar al alumnado a la Geografía de manera que ésta se "convierte" en una disciplina (área) cercana.

- La introducción de las nuevas tecnologías como Internet y Google Earth, en el aula de secundaria y en las clases de Ciencias Sociales en particular, supone una mayor atracción del alumnado hacia la Geografía y también respecto de la enseñanza en general. Así pues, Google Earth permite al profesorado "enganchar" a sus alumnos, 
atraerlos y despertar en ellos el interés por la disciplina Geográfica. Es pues una herramienta útil para enseñar.

- Google Earth se erige así como base para el estudio "de campo" de los elementos físicos y humanos analizados en la ciencia geográfica, sin moverse del aula. El uso de Google Earth en clase de Geografía (e Historia) es una ventana abierta a la realidad palpable, al medio en el que el ser humano se desarrolla, transforma, modifica...permitiendo, además, compaginar la base cartográfica (coordenadas geográficas, mapas políticos, mapas físicos, etc.) con la realidad existente en un lugar concreto, en un momento determinado.

-La utilización de esta nueva herramienta acompaña al profesorado en sus explicaciones unión teoría (contenidos geográficos conceptuales y teóricos) con la praxis (observación directa de dichos contenidos y definiciones y elaborando ellos mismos "viajes virtuales" por el territorio físico estudiado). Así permite analizar, de una manera unida y no sesgada, todos los elementos que intervienen en el estudio de la ciencia Geográfica.

- Trabajar con Google Earth a través de mini proyectos permite hacer hincapié en el objetivo antes citado de unir teoría y práctica. Logrando que la disciplina Geográfica no sea un estudio estanco del medio físico separado y aislado de la parte humana. Consiguiendo así que el alumnado asimile mejor los contenidos (conceptuales y procedimentales) y despertando en él una actitud positiva, de utilidad, de la Geografía como área de estudio que le acerca al medio vivido (su calle, su barrio, su ciudad, su país...).

- Google Earth logra también trabajar de una manera constructiva pues parte de la base de los conocimientos previos del alumnado, de aquello que conoce de manera directa como una ciudad (para el caso del alumnado urbano), de un área rural o semi rural (para el alumnado rural) o de un espacio rururbano o periurbano, etc. De esta manera, trabajando con una pedagogía constructivista, los nuevos contenidos se aprenden más fácilmente y que perduren en la imagen mental del alumnado para seguir construyendo sobre ellos.

- Al tratarse de una herramienta Web 2.0, logra que el alumnado participe y elabore información que puede añadir a la herramienta. De este modo le da valor añadido en tanto en cuanto el alumnado construye y elabora elementos que pueden también visualizar otras personas cuando utilicen Google Earth. Esto obliga a que la nueva información que el alumnado incorpora a Google Earth, debe ser una información con base científica, contrastada y trabajada, lo que les obliga a documentarse y buscar en fuentes diferentes para elaborar su nuevo material. El alumnado deja así de ser un mero observador y se convierte en un "productor" de conocimientos que se comparten.

- Enseñar Geografía (e Historia) con Google Earth permite al profesorado alcanzar los contenidos y objetivos diseñados en el currículo de secundaria obligatoria contando para ello con una base de imágenes que ayudan a lograrlo y que hacen que la disciplina geográfica sea real no algo inventado al cotejar lo expuesto en clase con imágenes de lugares conocidos por el alumnado. 


\section{NOTAS}

[1] Wikipedia: es un proyecto de la Fundación Wikimedia (sin ánimo de lucro) para construir una enciclopedia libre y políglota. Los más de 16 millones de artículos de Wikipedia han sido redactados conjuntamente por voluntarios de todo el mundo, y prácticamente todos pueden ser editados por cualquier persona que pueda acceder a Wikipedia. Iniciada en enero de 2001 por Jimmy Wales y Larry Sanger es actualmente la mayor y más popular obra de consulta en Internet. $<\underline{\text { http://es.wikipedia.org/wiki/Google_Earth }>}$

[2] Según DECRETO 112/2007, de 20 de julio, del Consell, por el que se establece el currículo de la Educación Secundaria Obligatoria en la Comunitat Valenciana. [2007/9717].

\section{BIBLIOGRAFÍA}

BARANSKI, N.N. Geografía general y geografía física y económica. Moscú: Memorias de la Sociedad de Geografía de la URSS, 1946, vol. 78, nº 1, pp. 9-24.

BONASTRA, Q. y JORI, G. El uso de Google Earth para el estudio de la morfología de las ciudades I. Ar@cne, Revista electrónica de recursos en Internet sobre Geografía y Ciencias Sociales, 2007. [En línea. Acceso libre]. Barcelona: Universidad de Barcelona, $\mathrm{n}^{\mathrm{o}} 100 .<$ http://www.ub.es/geocrit/aracne/aracne-100.htm $>$

BONASTRA, Q. y JORI, G. El uso de Google Earth para el estudio de la morfología de las ciudades II.Ar@cne, Revista electrónica de recursos en Internet sobre Geografía y Ciencias Sociales, 2007. [En línea. Acceso libre]. Barcelona: Universidad de Barcelona, $\mathrm{n}^{\mathrm{o}}$ 123. < $\underline{\text { http://www.ub.es/geocrit/aracne/aracne-101.htm }>}$

BROWN, M.C. Hacking Google Maps and Google Earth. Estados Unidos: Extremetech, 2010, pp. 408.

CAPEL, H. La enseñanza digital, los campus virtuales y la Geografía.RevistaAr@cne, Revista electrónica de recursos en Internet sobre Geografia y Ciencias Sociales, 2009. [En línea. Acceso libre]. Barcelona: Universidad de Barcelona, $\mathrm{n}^{\mathbf{0}} 125$. $<\underline{\text { http://www.ub.es/geocrit/aracne/aracne-125.htm }>}$

DANS, E. Todo va a cambiar. Tecnología y evolución: adaptarse o desaparecer. Deusto: EGEDSA, 2010, pp. 279.

MATEO, J.M. y Da SILVA E. V. Para una interpretación epistemológica de la Geografía a partir de la Dialéctica. La Habana: Mercator, Revista de Geografia da UFC, 2006, Número 09, pp. 55 - 68.

MORENO LACHE, N. et al. Itinerarios geográficos en la escuela: Lecturas desde la virtualidad. Colombia: Geopaideia, 2001, pp. 335.

NAFRÍA, I. Web 2.0. El usuario, el nuevo rey de Internet. Madrid: Gestión 2000, 2008, pp. 376.

RODRÍGUEZ COBANO, A.D. Aplicación de las nuevas tecnologías: la enseñanza de la Geografía. Revista Digital de Educación: Mundo Educativo, 2008. [En línea. Acceso libre], no 26, pp. 12.

$<\underline{\text { http://ecoem.com/administracion/revista/01b_Mundo_Educativo_26.pdf }>}$ 
SÁNCHEZ ÁGUILA-COLLANTES, J.J. La vuelta al mundo en 80 cliks. Revista electrónica: Rincón de Internet, 2006 [En línea. Acceso libre] no 159, pp. 76-78. $<\underline{\text { http://www.coit.es/publicaciones/bit/bit159/76-78.pdf }>}$

VUSCOVICH TOLEDO, M. Desarrollo de un sistema de información geográfica (SIG), basado en Google Earth, con fines agricolas. Chile: Facultad de Ingeniería Agrícola., Universidad de Concepción, 2008, pp. 125.

ZAPPETTINI, M.C. y ZILIO,C.K. La enseñanza de la Geografía con la incorporación de las nuevas tecnologías: Google Earth. [En línea. Acceso libre] Argentina: Facultad de Humanidades y Ciencias de la Educación. Universidad Nacional de la Plata. 2009, $<\underline{\text { http://egal2009.easyplanners.info/area03/3288_Zappettini_Maria_Cecilia.doc }>}$ 